\title{
Review Article \\ Investigation Progresses and Applications of Fractional Derivative Model in Geotechnical Engineering
}

\author{
Jinxing Lai, ${ }^{1}$ Sheng Mao, ${ }^{1}$ Junling Qiu, ${ }^{1}$ Haobo Fan,, Qian Zhang, \\ Zhinan $\mathrm{Hu}^{2}{ }^{2}$ and Jianxun $\mathrm{Chen}^{1}$ \\ ${ }^{1}$ School of Highway, Chang'an University, Xian 710064, China \\ ${ }^{2}$ School of Civil Engineering, Shijiazhuang Tiedao University, Shijiazhuang 050043, China \\ Correspondence should be addressed to Junling Qiu; 870133597@qq.com and Jianxun Chen; chenjx1969@chd.edu.cn
}

Received 1 February 2016; Accepted 7 April 2016

Academic Editor: José A. T. Machado

Copyright (c) 2016 Jinxing Lai et al. This is an open access article distributed under the Creative Commons Attribution License, which permits unrestricted use, distribution, and reproduction in any medium, provided the original work is properly cited.

\begin{abstract}
Over the past couple of decades, as a new mathematical tool for addressing a number of tough problems, fractional calculus has been gaining a continually increasing interest in diverse scientific fields, including geotechnical engineering due primarily to geotechnical rheology phenomenon. Unlike the classical constitutive models in which simulation analysis gradually fails to meet the reasonable accuracy of requirement, the fractional derivative models have shown the merits of hereditary phenomena with long memory. Additionally, it is traced that the fractional derivative model is one of the most effective and accurate approaches to describe the rheology phenomenon. In relation to this, an overview aimed first at model structure and parameter determination in combination with application cases based on fractional calculus was provided. Furthermore, this review paper shed light on the practical application aspects of deformation analysis of circular tunnel, rheological settlement of subgrade, and relevant loess researches subjected to the achievements acquired in geotechnical engineering. Finally, concluding remarks and important future investigation directions were pointed out.
\end{abstract}

\section{Introduction}

In practical engineering, massive unstable failure is closely related to the rheological characteristic of rock and soil. Recently, owing to guarantee of the long-term safety and stability of geotechnical engineering, an increasing attention has been paid by relevant scholars to the investigations on the rheology, whose core content is constitutive model [1, 2]. Generally, the classical constitutive model for rock and soil can be classified into three distinct approaches, namely, empirical and semiempirical models, rheology theory based models, and visco-elastic-plastic component models. The empirical and semiempirical models, which are based on experiments, were endowed with a small number of parameters. On the other hand, the rheology theory based models, which focus on the mechanical response, thus reveal the properties of rheology at the microscale. The visco-elasticplastic component model, as a common approach, which is composed of standard elements such as the Hooke spring and the Newtonian dashpot, has the advantage of flexible description of different rheology deformation with visual concept and clear physical significance [3-6]. Nevertheless, the empirical and semiempirical models are restricted by the duration of experiment, whose results can only describe the stable stage of creep. Meanwhile, the visco-elastic-plastic component models require more elements to establish constitutive equations so as to meet precision requirement [7], causing the problems of many parameters, complicated constitutive relation, and difficulty in determination of parameters, resulting in inconvenience for actual engineering. On the whole, because of its natural defects, the classical models have difficulty in characterizing accurately the whole process curve of creep of rock and soil. Specifically, at the primary stage of creep, its theoretical values deviate much from the experimental results, especially if the accelerated stage appears subsequently $[8,9]$.

As a result, more and more investigators employ fractional calculus to the establishment of constitutive models when obtaining a model with a small number of parameters and accurate description is the target point [10-12]. 
In fact, during last decades, the field of fractional calculus has attracted increasing interest of researchers in very diverse scientific fields including mathematics, chemistry, engineering technology, anomalous diffusion, and even medical machinery and robot control [13-19]. Indeed, fractional calculus which is defined in the form of calculus with concise equation has been found to be an accurate mathematical tool for solving the difficulty during physical and mechanical modeling. As for the rheology, which is featured by time dependency, the fractional derivative model can be a perfect approach for describing rheology phenomenon, in particular to the properties of hereditary phenomena with long memory $[20,21]$. Over the years, after devoting many continuous efforts toward the study on the application of fractional calculus by numerous researchers, the fractional derivative model has gained much deep development. Specific to the parameters, which are the key point in the process of application and to determine the feasibility of model, it can be obtained through inversion based on experiment data, numerical calculation, and software fitting. As a distinct approach, fractional derivative model is applied to describe the nonlinear viscoelastic property, deformation property, shear contraction and dilatation, and damage growth during accelerated stage of creep in geotechnical engineering $[9,22$, 23]. For more details on the creep phenomena, fractional derivative model is regarded as an effective approach that can not only well reflect the process of nonlinear gradual change at primary stage but also present accurately at steady stage and accelerated stage under high stress. However, due to its pseudodifferential operator, the storage memory property of fractional derivative model brings certain difficulty to numerical calculation despite the fact that the rheological process curve is beautifully presented [24].

In this paper, we systematically investigated current research in the field of fractional derivative model structure and acquisition of parameters where the resulting models had been incorporated into creep analysis. We began with an introduction to relevant concepts and developments of fractional calculus, providing an up-to-date review of key constitutive models which had been widely applied in the field of geotechnical engineering. Following this we comprehensively reviewed the state of the art subjected to practical applications of fractional derivative model, including three major aspects of deformation analysis of circular tunnel, rheological settlement of the subgrade, and relevant loess researches.

\section{Model Structure Research}

2.1. Presentation and Development of Fractional Calculus. The fractional calculus has been verified, that is, a branch of mathematics which investigates the property of the differentiation and integration of any order. Its embryonic form can be dated back to September 30, 1695, when Leibniz replied to the famous question: "What does the derivative $d^{n} f / d x^{n}$ for $f(x)$ mean if $n=1 / 2$ ?" proposed by L' Hospital [25]. Due to its complicated calculation and undefined physical significance, the focus at early stage is mainly on research in pure mathematics, and for a long period of time, the research on fractional calculus has attracted little attention from scholars in natural science and engineering technology field. In 1936, Gemant firstly applied fractional derivatives to problems in elasticity [26]. Until 1982, Mandelbrot [27] who was the founder of fractal theory pointed out that there was a self-similarity phenomenon between integer and fraction, and many fractal dimensions existed in nature and many technological sciences. Subsequently, researchers found relevant phenomenon or process of fractal geometry, power law phenomenon, and memory process, which could establish a close relationship with fractional calculus, thus leading to an explosion of research activities on fractional calculus. The contribution of Shestopal and Goss [28] was firstly applied to fractional derivative in Maxwell and Kelvin model for analysis of creep buckling. Bagley and Torvik [29] conducted research on three-dimensional constitutive relation of fractional derivative, limitation of thermodynamics on model parameters, and finite element method. Through utilizing the linear standard system of fractional derivative, Zhang [30] established the constitutive relation of nitrile rubber and proved that it was equivalent with Rabotnov model. Metzler and Nonnenmacher [31] took Zener model based on fractional order to explore the abnormal relaxation of polymeric materials. Yin et al. [32] firstly considered fractional derivative element as soft-matter element while building the constitutive model of soil rheology phenomena, representing the material between an ideal fluid and an ideal solid.

Up to now, there are many different definitions of fractional calculus [33-35], among which basic ideology is to look at a fractional derivative as the inverse operation of a fractional integral. It is usually chosen as the RiemannLiouville form:

$$
\begin{array}{rl}
\frac{d^{-\gamma} f(t)}{d t^{-\gamma}}={ }_{t_{0}} D_{t}^{-\gamma} f(t)=\int_{t_{0}}^{t} \frac{(t-\xi)^{\gamma-1}}{\Gamma(\gamma)} f(\xi) d \xi, & \\
t & t \in\left[t_{0}, b\right],
\end{array}
$$

where $f(t)$ is integrable function on the interval $\left[t_{0}, b\right]$ with the order $\gamma>0, n-1<\gamma \leq n$ ( $n$ is integer) and $\Gamma(\gamma)$ is Euler's Gamma function, which is defined by

$$
\Gamma(\gamma)=\int_{0}^{\infty} e^{-t} t^{\gamma-1} d t
$$

Correspondingly, the Riemann-Liouville fractional derivative is given by

$$
\frac{d^{\gamma} f(t)}{d t^{\gamma}}={ }_{t_{0}} D_{t}^{\gamma} f(t)=\frac{d^{n}}{d t^{n}}\left[{ }_{t_{0}} D_{t}^{-(n-\gamma)} f(t)\right] .
$$

Laplace transformation formula of fractional differential can be expressed as

$$
\begin{array}{cl}
L\left[{ }_{0} D_{t}^{-\gamma} f(t), p\right]=p^{-\gamma} \bar{f}(p), \quad \gamma \geq 0, \\
L\left[{ }_{0} D_{t}^{\gamma} f(t), p\right]=p^{\gamma} \bar{f}(p), \quad \gamma \leq 0,
\end{array}
$$

where $f(t)$ can be integrated near $t=0$ with $0 \leq \gamma \leq 1$ and $\bar{f}(p)$ is Laplace transformation of $f(t)$. 


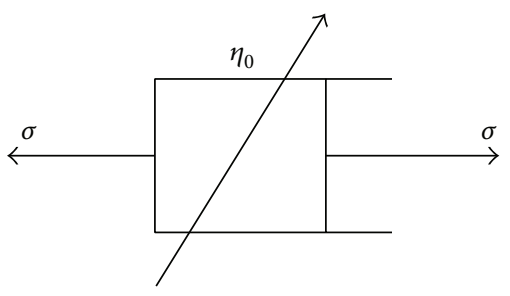

FIGURE 1: Abel dashpot with constant coefficient [32].

2.2. Research Achievements of Model Structure. Just as fractional calculus is a generalization of the commonly used integer-order differentiation and integration, fractional derivative model continues classical model's feature of being concise and easy to understand, which not only can make up the shortcomings of classical model but also has better description effects. Its essence is to replace a Newtonian dashpot in classical model with the fractional derivative Abel dashpot and thus obtain fractional derivative model through series-parallel connection with other several basic elements. In geotechnical engineering, the functional equations of fractional model are mainly utilized to perform the process curve of rheology phenomena, with an attempt to adjust deformation rate and control the stress (strain) [36, 37].

2.2.1. Fractional Derivative Abel Dashpot Research. There are two kinds of most basic kernel operators: Abel kernel and Rabotnov kernel. The fractional derivative element established based on Rabotnov kernel has the advantage of describing rheological curve with horizontal asymptote, but its equations are quite complicated, resulting in hardly acquired parameters. For a comparison, using Abel kernel to investigate creep phenomenon, the basic ideology is to research the function forms after derivation of creep compliance for modified Abel dashpot. Its relevant model has fewer parameters and stronger adaptability, which is demonstrated by the increasing number of papers and special issues in journals [38-43].

Function equation of Abel kernel [36] is written as follows:

$$
\phi(t)=\frac{\lambda t^{-\gamma}}{\Gamma(1-\gamma)} .
$$

(1) Abel Dashpot with Constant Coefficient. The constitutive equation of Abel dashpot with constant coefficient shown in Figure 1 is defined as follows:

$$
\sigma(t)=\eta^{\gamma} \frac{d^{\gamma}[\varepsilon(t)]}{d t^{\gamma}} \quad(0 \leq \gamma \leq 1)
$$

where $\eta^{\gamma}$ is the viscosity coefficient. In a special case of $\gamma=$ 1 , the constitutive equation (6) is usually applied to describe the Newton dashpot, being equivalent to an ideal fluid with $\eta^{\gamma}=\eta$, while a spring in the case of $\gamma=0$ is equivalent to an ideal solid with $\eta^{0}=E$. Therefore, Abel dashpot with constant coefficient bridges the gap between an ideal fluid and an ideal solid material response by interpolating between the Newton dashpot and a spring.

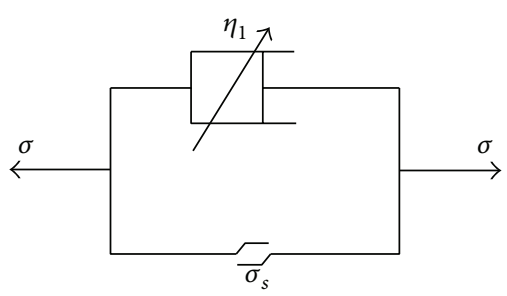

Figure 2: Abel dashpot with variable coefficient [2].

Under the circumstance of constant stress in (6), namely, $\sigma(t)=\sigma$, the element denotes the creep strain characteristic. Conducting the fractional integral calculation of (6) based on the Riemann-Liouville operator, we can gain

$$
\varepsilon(t)=\frac{\sigma}{\eta^{\gamma}} \frac{t^{\gamma}}{\Gamma(1+\gamma)} \quad(0 \leq \gamma \leq 1) .
$$

(2) Abel Dashpot with Variable Coefficient. During the process of rheology, in particular at the accelerated stage, the cracking and damage growth at the microscale must be considered; hence, the viscosity coefficient of rock or soil is no longer remaining unchanged, which should be described by introducing the damage variable $[2,44,45]$. As a result, the constitutive relation of Abel dashpot with variable coefficient shown in Figure 2 deduces that

$$
\sigma(t)=\left[\eta^{\gamma}\left(1-D_{\omega}\right)\right] \frac{d^{\gamma}[\varepsilon(t)]}{d t^{\gamma}} \quad(0<\gamma \leq 1),
$$

where $D_{\omega}$ is the damage variable defined by $0 \leq D_{\omega}=$ $1-e^{-\alpha t}<1$ and $\eta^{\gamma}\left(1-D_{\omega}\right)=\eta^{\gamma} e^{-\alpha t}$ indicates the variable viscosity coefficient; $\alpha$ is related to properties of materials.

2.2.2. Application of Fractional Derivative Model. In terms of the issues in geotechnical engineering, fractional derivative models are usually composed of basic element, constant coefficient Abel dashpot, and variable coefficient Abel dashpot in series and parallel, which now have evolved from simple models such as fractional Maxwell and Kelvin models to the fractional Nishihara model accounting for the efforts researchers devoted. In contrast, the simple models are connected in series or in parallel with the constant coefficient Abel dashpot and spring element, while the three elements' solid model in series with variable coefficient dashpot leads to the fractional Nishihara model. Additionally, three-dimensional constitutive equation is derived from onedimensional constitutive equation of fractional derivative models. The commonly used models are shown in Figure 3.

Note that different rheological conditions require different models. In Figure 3, (a), (b), (c), and (d) belong to viscoelastic model, while (e) belongs to viscoelastoplastic model. In greater detail, (a), (b), and (c) are all suitable for describing creep that tends to stability finally and (c) shows the highest fitting precision. For comparison, (d) has advantage of describing the creep with decay and flow period; (e) is regarded as special one that can approach the three stages with initial stage, stable stage, and accelerated stage.

Taking the relevant investigations on soft soil as examples showing the evolution of model structure, Sun and Zhang 


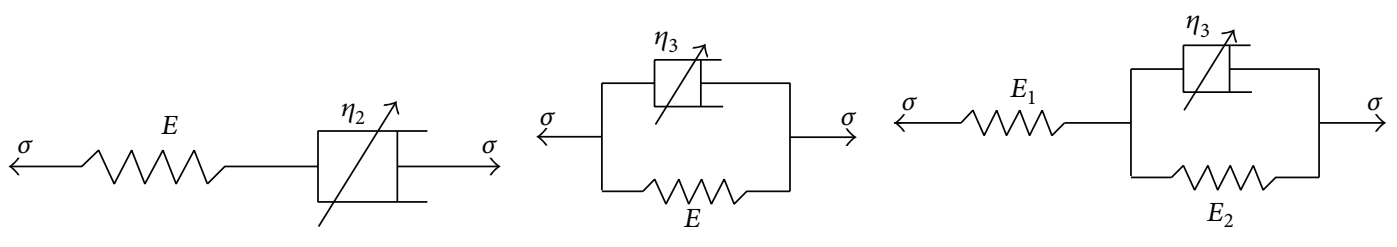

(a) The Maxwell model

(b) The Kelvin model

(c) The three elements' solid model (KelvinVoigt)

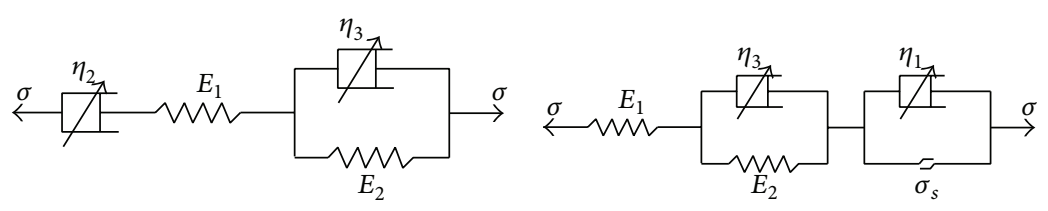

(d) The Burgers model

(e) The Nishihara model

FIGURE 3: The fractional derivative element model [36].

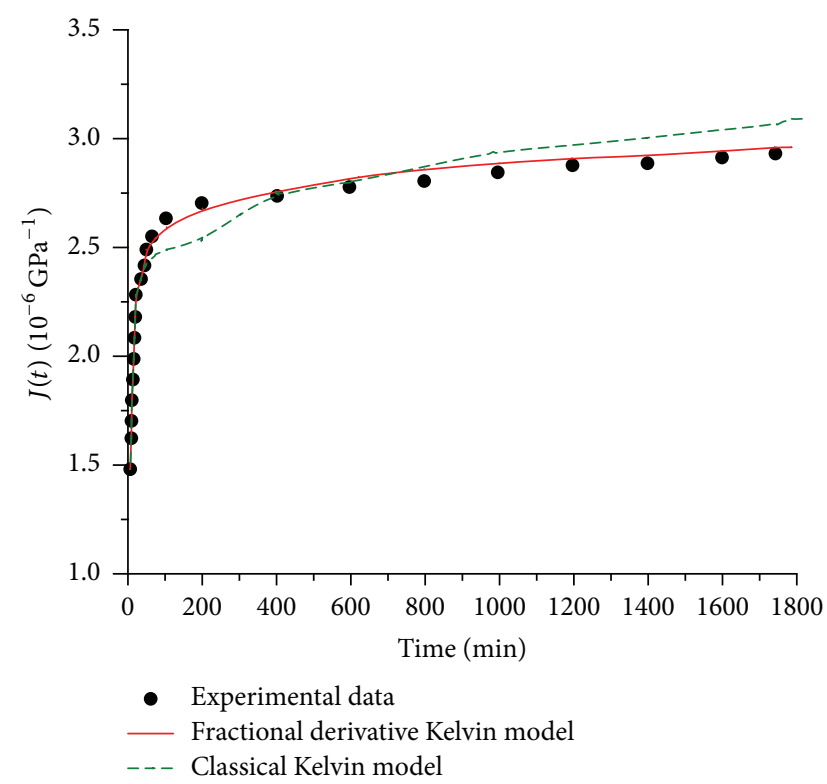

FIGURE 4: Curves, respectively, simulated by fractional Kelvin model and Kelvin model $(\sigma=37.5 \mathrm{kPa})[46]$.

[46] adopted the fractional derivative Kelvin model, as shown in Figure 3(b), to simulate the creep laws of two stages of soft soil in Pearl River Delta, in which equation form was simple and unified compared with classical model. Additionally, fewer parameters needed to be adjusted during the process of calculation. In addition, from the results shown in Figure 4, the classical Kelvin model brings a large deviation in comparison with the experimental data near the inflection point of fitted curve, and its offset increases with the time. It can be predicted that accordingly, in a very long time, the classical Kelvin model is seriously out of accordance with the experimental data.

Based on fractional calculus theory, Li and Yue [47] proposed a five-element nonlinear rheological constitutive model, which reserved a Newton dashpot, as shown in Figure 5, for Hong Kong marine clay and Shanghai mucky clay under different stress levels. When $\sigma_{0}<\sigma_{s}$, the right side

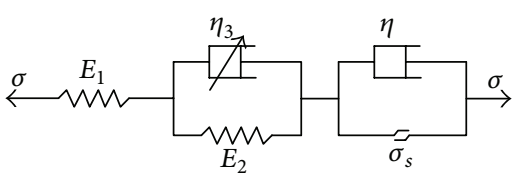

FIgURE 5: Fractional order derivative five-element model [47].

of the viscoplastic dashpot does not participate in the work; thus the model is simplified as fractional derivative threeelement solid model. While $\sigma_{0}>\sigma_{s}$, the viscoplastic dashpot participates in the work; the model can better characterize the three stages of soft soil under high stress with high fitting accuracy, in which relevant coefficient of the whole curve compared with experimental results reaches 0.9696, shown in Figure 6. In this regard, the model has wide applicability in view simultaneously of a small number of parameters which are easy to determine.

To research creep properties of Zhanjiang soft clay, He et al. [48] built the modified Burgers model, and then the expression of three-dimensional equation was derived based on hereditary creep theory. Consider

$$
\varepsilon_{i j}=\frac{s_{i j}}{2 G}+\frac{\sigma_{m}}{3 k} \delta_{i j}+\frac{s_{i j}}{2 G} \int_{0}^{t} \kappa(t) d t
$$

where $s_{i j}$ is the deviator stress tensor and $G$ indicates the shear modulus. $\sigma_{m}$ is the confining pressure and $k$ expresses the bulk modulus of deformation. In a special case of $i=j$, $\delta_{i j}=1$, while $\delta_{i j}=0$ in another case.

\section{Determination of Model Parameters}

Simplicity and accuracy are two significant benchmarks to measure the applicability of constitutive model [39-41]. Lewandowski and Chorążyczewski [42] pointed out that an important problem, connected with the fractional rheological models, is an estimation of the model parameters from experimental data. To some extent, the key to accurately apply the fractional derivative model to practical engineering lies in the precision of fitting parameters $[42,43]$. 
TABLE 1: Characteristics of the commonly used rheological model of fractional derivative.

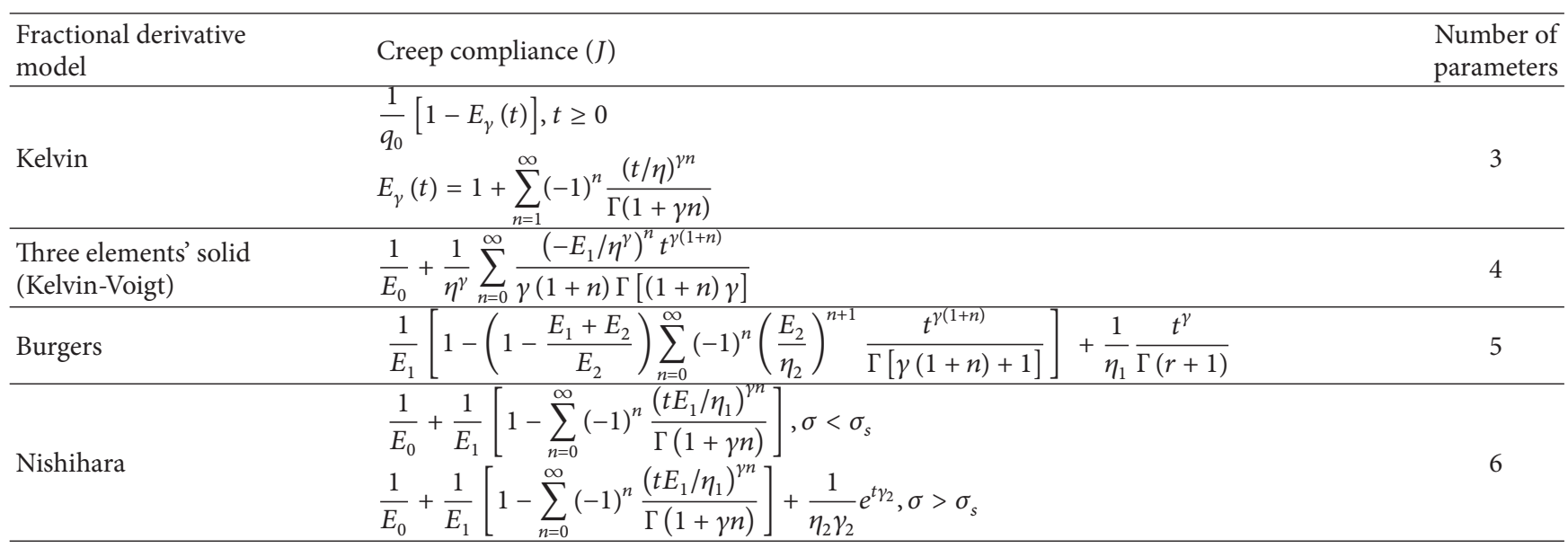

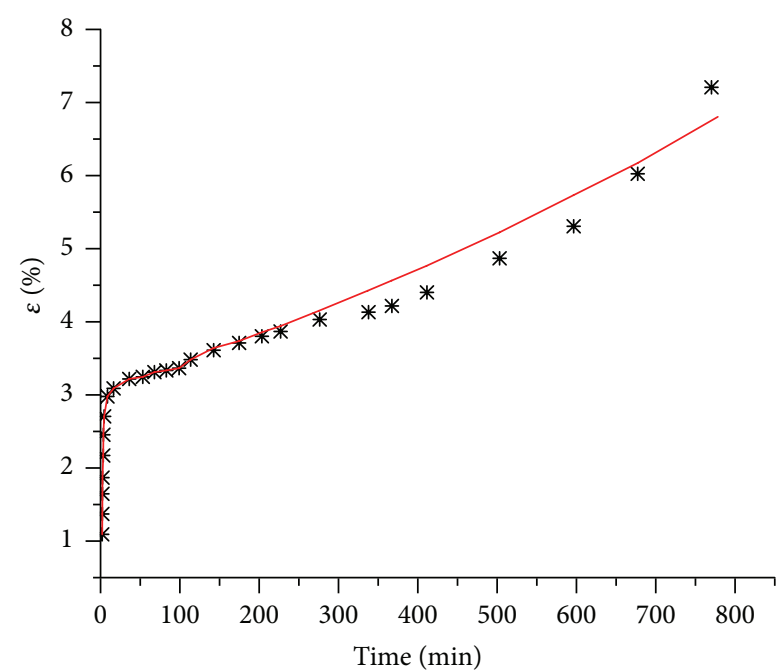

* Experimental values

— Fractional derivative Nishihara model

Figure 6: Test data and fitting curve of five-element fractional derivative model $(\sigma=243 \mathrm{kPa})$ [47].

Literature [25] investigated that the creep equations of different models have unified form given by

$$
\varepsilon(t)=J(t) \sigma,
$$

where $J(t)$ refers to creep compliance, which have different forms. Their forms [49-52] and the number of parameters are summarized in Table 1.

3.1. Parameters Identification with Method of Numerical Analysis. Generally, the numerical methods for determining the parameters of rheological model mainly include regression inversion method, least square method, and decomposition method based on rheological curve. Nevertheless, all these optimized algorithms have some restricted conditions when dealing with relevant issues; that is, the optimized function of constitutive relation should be differentiable. Along with the rapid development of numerical calculation and analysis,
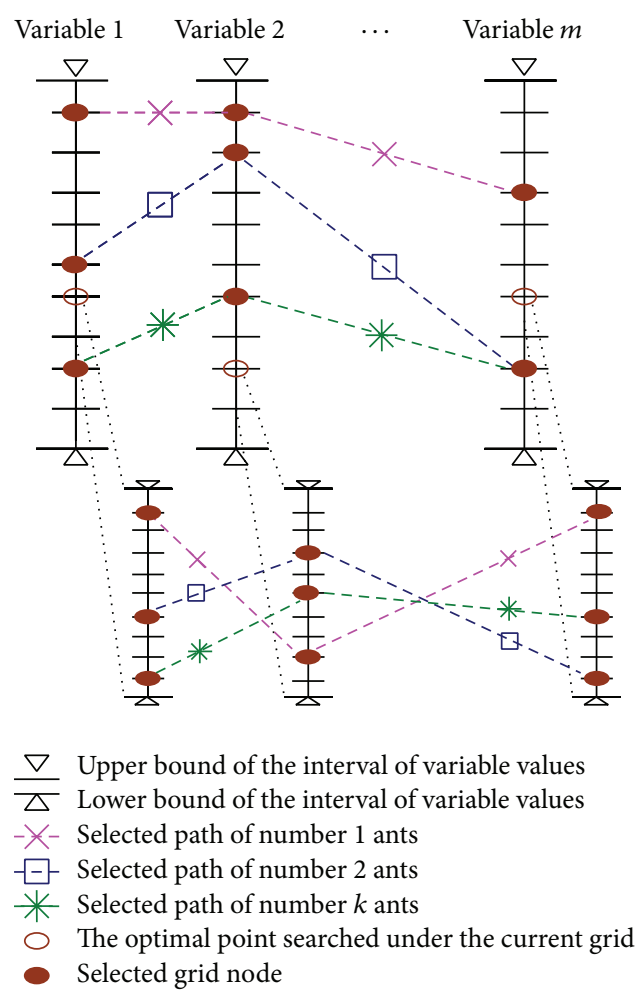

FIGURE 7: Ant colony algorithm [53].

the estimation of the fractional derivative model has been brought to a whole new level.

3.1.1. Ant Colony Algorithm. Specific to the interval variables of parameters in viscoelastic Voigt constitutive model that was the fractional derivative three elements' solid model, Zhao [53] firstly established the solving models for parameters, including the semianalytical finite element model based on time domain homogenous field and the difference finite element model on the basis of regional heterogeneous field. And then using optimized algorithm depended on ant colony theory, as shown in Figure 7; the single and combined identification of constitutive parameters all was realized. 


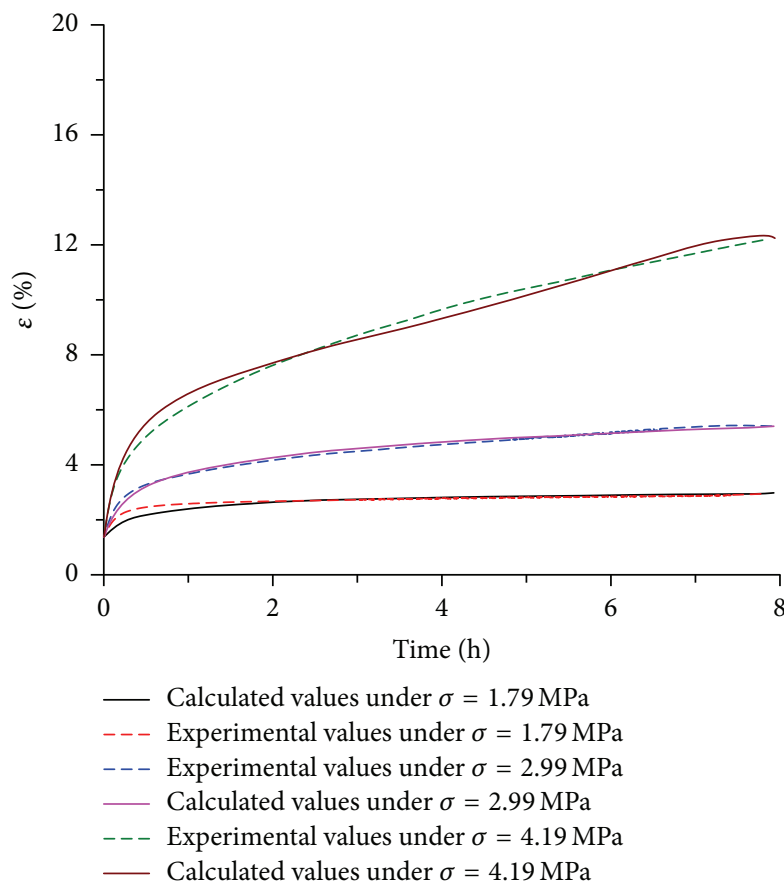

(a) Fractional derivative Kelvin model

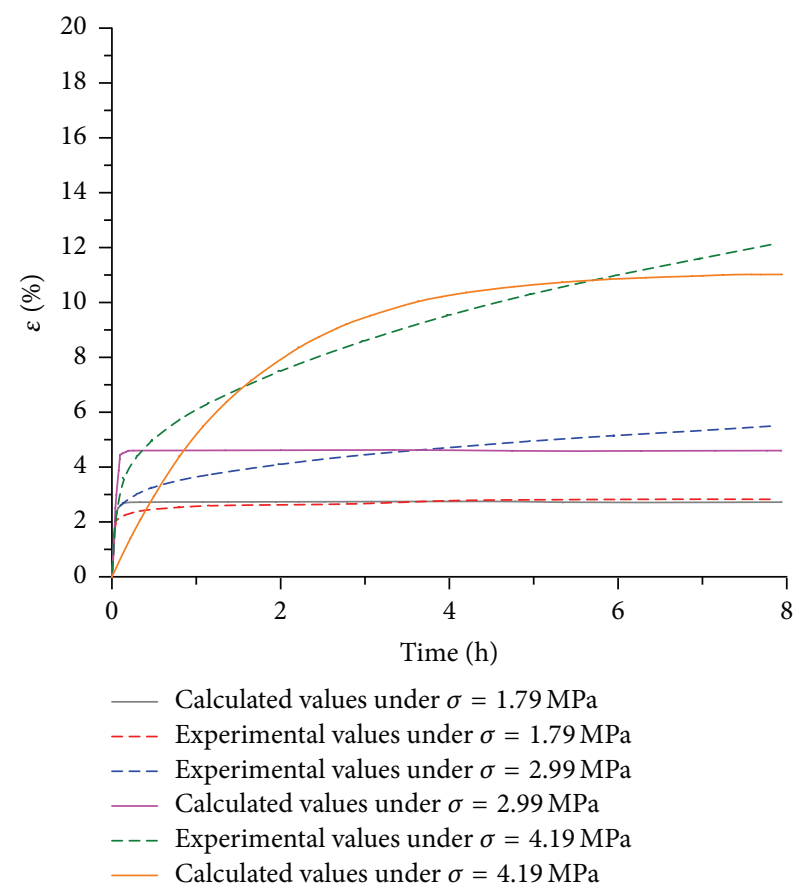

(b) The Kelvin model

FIGURE 8: Calculation value of frozen soil and the uniaxial creep test value contrast [36].

TABLE 2: Particle swarm parameters [55].

\begin{tabular}{lcccc}
\hline Populations & $\begin{array}{c}\text { Close to } \\
\text { populations }\end{array}$ & $C_{1}$ & $C_{2}$ & $\begin{array}{c}\text { Maximum } \\
\text { acceleration }\end{array}$ \\
\hline 80 & 15 & 3.0 & 3.0 & 15 \\
\hline
\end{tabular}

3.1.2. Genetic Algorithm. In order to address the uniaxial creep of artificially frozen soil in the area of Huainan-Huaibei, Wang [36] adopted fractional derivative Kelvin model to simulate the creep characteristics of the first and second stages and then obtained the model parameters through global optimization based on genetic algorithm. As shown in Figure 8, fractional derivative Kelvin model has a higher accuracy of simulation than the classical Kelvin model. In contrast to test data, the former has the relevant coefficient of more than 0.99 .

3.1.3. Particle Swarm Optimization Algorithm. Chen et al. [54] applied particle swarm optimization for the purpose of identifying the creep parameters of generalized Kelvin model, which was built with the experimental data on steady stage of artificially frozen soil under different loading stress; thus material parameters of generalized Kelvin model were obtained.

Similarly, Niu [55] built the fractional derivative Nishihara model intended to describe the deformation of frozen soil at accelerating rheology stage; furthermore, particle swarm optimization was applied to optimize the parameters of fractional derivative creep model. The parameters using particle swarm optimization algorithm were shown in Table 2 .
Special to the experiment conditions, sandy clay had the loading values of $0.7 \sigma_{s}$, respectively, at the temperature of $-5^{\circ},-10^{\circ}$, and $-15^{\circ}$. The obtained parameters of the fractional derivative Nishihara model were shown in Table 3. As a result, the relevant coefficient for fitting model parameters through particle swarm optimization algorithm was more than 0.98 , which highlighted the unique advantage of particle swarm optimization algorithm in application of optimizing the fractional derivative Nishihara model for describing accelerating rheology of frozen soil.

3.1.4. Intelligence Algorithm. Simulated annealing (SA) algorithm $[56,57]$ was incorporated into standard particle swarm optimization (PSO) algorithm by $\mathrm{Xu}$ et al. [58], which could minimize the error caused by the limitations of PSO algorithm. The new method obtained was called SAPSO algorithm, as shown in Figure 9. Since PSO algorithm only accepts the optimal solution, point $A$ in Figure 9 will fall into the local optimal solution on the left during the calculating, resulting in the global optimal solution being usually neglected. Subjected to the SA algorithm, point $A$ can be only accepted with a certain probability. Therefore, point $B$ as the global optimal solution has opportunity to be obtained by getting out of the local optimal solution.

After optimization, rheological curve decompositionparticle swarm-simulated annealing algorithm is established to inverse the multiparameter constitutive model of rock rheology, leading to effectively solving the initial value dependence of nonlinear problem and gaining global optimal solution simultaneously. Additionally, we can obtain from Figure 10 that SAPSO algorithm shows rapid changes with 
TABLE 3: Parameters of particle swarm fractional order derivative Nishihara model [55].

\begin{tabular}{|c|c|c|c|c|c|c|c|c|}
\hline Soil & Temperature & $\begin{array}{c}\text { Loading } \\
\text { coefficient }\end{array}$ & $\sigma$ & $E_{1}$ & $\eta_{2}$ & $\gamma$ & $\sigma_{s}$ & $\begin{array}{c}\text { Correlation } \\
\text { coefficient }\end{array}$ \\
\hline \multirow{9}{*}{ Clay } & \multirow{2}{*}{-5} & 0.3 & 1.05 & 0.06 & - & 0.1116 & - & 0.9869 \\
\hline & & 0.5 & 1.75 & 0.28 & - & 0.72 & - & 0.9990 \\
\hline & \multirow{2}{*}{-10} & 0.3 & 1.5 & 0.24 & - & 0.0068 & & 0.9943 \\
\hline & & 0.5 & 2.5 & 1.16 & & 0.0198 & - & 0.9947 \\
\hline & \multirow{2}{*}{-15} & 0.3 & 2.1 & 0.65 & - & 0.3119 & - & 0.9966 \\
\hline & & 0.5 & 3.5 & 0.18 & - & 0.3901 & - & 0.9992 \\
\hline & -5 & 0.7 & 2.45 & 0.000646 & 0.000631 & 1.0494 & 2.37 & 0.9919 \\
\hline & -10 & 0.7 & 3.5 & 0.11854 & 1.0638 & 0.00811 & 3.25 & 0.9873 \\
\hline & -15 & 0.7 & 4.9 & 0.01117 & 0.00548 & 1.139 & 4.74 & 0.9927 \\
\hline
\end{tabular}

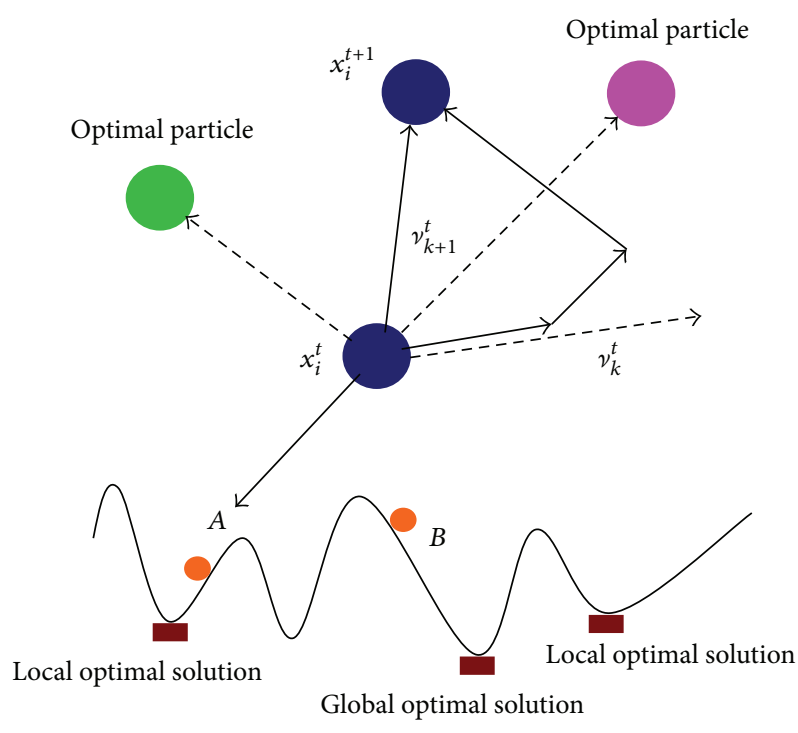

FIGURE 9: Sketches of SAPSO algorithm [58].

fitness value in the first 16 iterative steps and then reaches a high convergence precision.

3.2. Parameter Solving Based on Software. Based on Monte Carlo, Gen et al. [59] took the minimum error of experimental data as the criterion and then made the experimental curves of nine samples fitted with standard fractional derivative linear model, thus determining the relaxation time and coefficient of viscosity of Malan loess. Meanwhile, Sun and Zhang [46] and Li and Yue [47] by means of MATLAB performed effective identification for parameters aspects of fractional derivative Kelvin model under the condition of low stress of soft soil and fractional derivative five-element model under the condition of high stress, which was featured by simplicity and wide applicability.

He [60] performed parameter fitting for fractional derivative Maxwell model through 1stOpt mathematical software shown in Figure 11. As a result, the changes law of rheological model parameters for $Q_{2}$ loess in cases of different water content was gained, as shown in Table 4 .
TABLE 4: Parameters fitting results of uniaxial rheological model of $Q_{2}$ loess in Yan'an [60].

\begin{tabular}{lccc}
\hline$\omega(\%)$ & $E_{0}\left(10^{5} \mathrm{kPa}\right)$ & $\eta\left(10^{5} \mathrm{kPa} \cdot \mathrm{min}\right)$ & $\gamma$ \\
\hline 5 & 3.029 & $57.093 \sigma^{-0.5813}$ & $0.0109 \sigma^{-0.3369}$ \\
7 & 1.361 & $11.068 \sigma^{-0.3529}$ & $0.0337 \sigma^{-0.1172}$ \\
10 & 1.109 & $16.234 \sigma^{-0.3711}$ & $0.0496 \sigma^{-0.0964}$ \\
12 & 0.787 & $3.1993 \sigma^{-0.1921}$ & $0.0265 \sigma^{-0.2053}$ \\
15 & 0.577 & $3.166 \sigma^{-0.3786}$ & $0.0122 \sigma^{-0.3588}$ \\
18 & 0.419 & $4.9773 \sigma^{-0.3832}$ & $0.026 \sigma^{-0.1839}$ \\
20 & 0.311 & $2.5315 \sigma^{-0.2093}$ & $0.0424 \sigma^{-0.1495}$ \\
22 & 0.229 & $1.2174 \sigma^{-0.1585}$ & $0.0238 \sigma^{-0.2741}$ \\
\hline
\end{tabular}

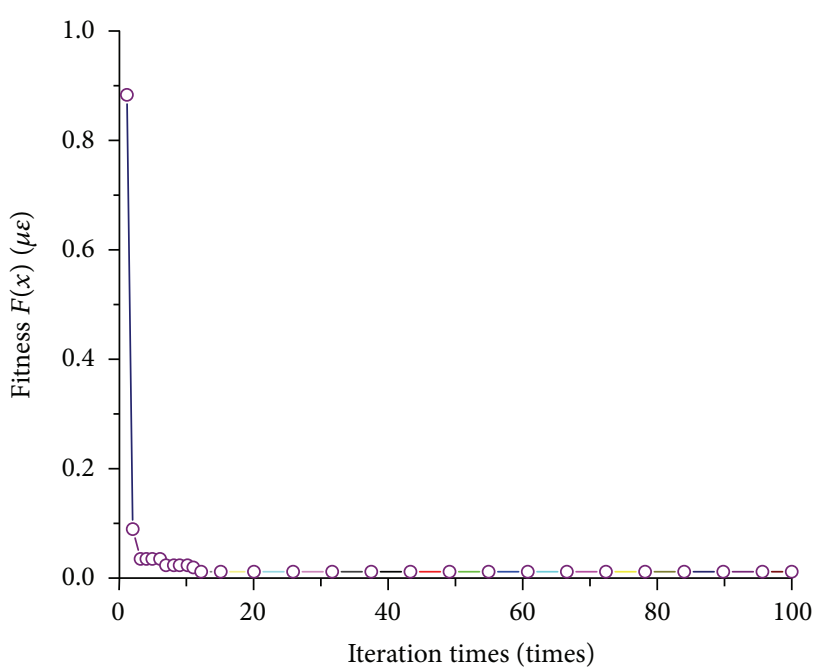

FIGURE 10: Relationship between fitness and iteration times [58].

On the basis of parameter identification, hence, constitutive equation of steady creep model for Yan'an $Q_{2}$ loess under the condition of uniaxial stress was obtained. Consider

$$
\varepsilon(t)=J_{\text {se }}(t) \sigma=\left(\frac{1}{E_{0}}+\frac{1}{\eta} \frac{t^{\gamma}}{\int_{0}^{\infty} e^{-t} t^{\gamma} d t}\right) \sigma, \quad \sigma<\sigma_{s},
$$

where $\sigma_{s}$ is determined by uniaxial creep experiment. 


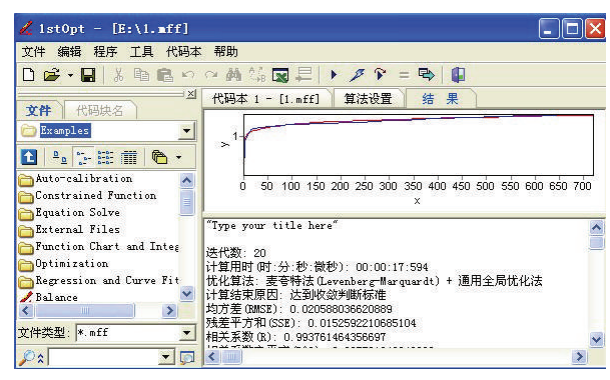

FIGURE 11: Interface of 1stOpt [60].

\subsection{Parameter Analysis}

3.3.1. Parameter Sensitivity Analysis. In order to get an adequate understanding of the effects of parameters $\gamma$ and $\alpha$ on the time-dependent strain and stress, Zhou et al. [61] applied programmable rheometer to carry out uniaxial rheological experiments for salt rock sample of well Wangchu-1 of Jianghan oilfield. Subsequently, based on the results of experiment, fitting analysis of parameters $\gamma$ and $\alpha$ on rheological strain was conducted and its effects were discussed simultaneously. Figure 12(a) shows that rheological value and rheological speed greatly depend on fractional derivative order, and, the higher the fractional derivative order, the higher the creep strain, which reflects the flexibility of fractional derivate model in description of rheology phenomena. Moreover, in the special case of $\alpha=0$, rheological procedures of salt rock never appear to be obvious accelerated stage as shown in Figure 12(b), namely, the third stage, which only appears in the case of $\alpha>0$. What is more, the accelerated stage is more likely to occur as the values of $\alpha$ increase. The results obtained mutually verify the conclusions of Xu et al. [58], Liu and Zhang [62], Yang and Fang [63], and He et al. [64].

3.3.2. Special Case. Introducing the Mittag-Leffler function, the equations based on the fractional derivative Nishihara model deduce that

$$
\mathcal{\varepsilon}(t)= \begin{cases}\frac{\sigma}{E_{0}}+\frac{\sigma}{E_{1}}-\frac{\sigma}{E_{1}} E_{\gamma, 1}\left(-\frac{E_{1}}{\eta_{1}^{\gamma}} t^{\gamma}\right), & \sigma \leq \sigma_{s} \\ \frac{\sigma}{E_{0}}+\frac{\sigma}{E_{1}}-\frac{\sigma}{E_{1}} E_{\gamma, 1}\left(-\frac{E_{1}}{\eta_{1}^{\gamma}} t^{\gamma}\right)+\frac{\sigma-\sigma_{s}}{\eta_{2}^{\gamma}} t^{\gamma} E_{1,1+\gamma}(\alpha t), & \sigma \geq \sigma_{s}\end{cases}
$$

where $E_{x, y}(z)$ is Mittag-Leffler function with the case of $E_{1,1}(z)=e^{z}$ and $E_{1,2}=\left(e^{z}-1\right) / z$.

In a special case of $\gamma=1$ and $\alpha=0,(12)$ is simplified as

$\varepsilon(t)$

$$
= \begin{cases}\frac{\sigma}{E_{0}}+\frac{\sigma}{E_{1}}\left(1-e^{-\left(E_{1} / \eta_{1}\right) t}\right), & \sigma \leq \sigma_{s}, \\ \frac{\sigma}{E_{0}}+\frac{\sigma}{E_{1}}\left(1-e^{-\left(E_{1} / \eta_{1}\right) t}\right)+\frac{\sigma-\sigma_{s}}{\eta_{2}} t, & \sigma \geq \sigma_{s} .\end{cases}
$$

Note that (13) refers to the constitutive relation of the classical Nishihara model. The classical Nishihara model is a special case of the fractional derivative Nishihara model accordingly [60]. The conclusion is mutually verified with the results of Yin et al. [32], He et al. [48], and Xu et al. [58].

\section{Engineering Application}

4.1. Deformation Analysis of Circular Tunnel. As the traditional issue of underground engineering, the stress of surrounding rock mass is redistributed due to tunnel excavation, resulting in occasionally a large delayed deformation that might lead to a delayed failure of structure and rock mass collapse, especially for the tunnel in soft rock [65, 66]. Therefore, the deformation mechanism of surrounding rock should be investigated in the perspective of rheology behavior, since the property of associated time effects.

Liu and Zhang [62] proposed to take advantage of fractional derivative Kelvin model to investigate the deformation properties of horizontal circular tunnel [67, 68]. With the analysis of the result, it was shown that fractional derivative model could perform the relaxation properties of viscoelastic rock mass. In addition, different viscoelastic rock could be precisely described through adjusting fractional order, which was proved to the conclusions as mentioned previously. The displacement and strain components of circular tunnel based on fractional Kelvin derivative model deduced that

$$
\begin{aligned}
& u(t)=\frac{a^{2} \sigma_{0}}{2 G r}\left\{1-E_{a}\left[-\left(\frac{t}{\tau}\right)^{\gamma}\right]\right\}, \\
& \varepsilon_{r}(t)=-\frac{a^{2} \sigma_{0}}{2 G r^{2}}\left\{1-E_{a}\left[-\left(\frac{t}{\tau}\right)^{\gamma}\right]\right\}, \\
& \varepsilon_{\theta}(t)=\frac{a^{2} \sigma_{0}}{2 G r^{2}}\left\{1-E_{a}\left[-\left(\frac{t}{\tau}\right)^{\gamma}\right]\right\} .
\end{aligned}
$$

Chen [69] took the effects of tunnel face into account, namely, the spatial effect, as shown in Figure 13; at the same time the region within quadruple tunnel radius from tunnel face was defined as the near section, contrarily as the far section. Using fractional derivative Maxwell model and classic Burgers model, respectively, comparative analyses on the displacement changed with time aspects after circular tunnel excavation and support were performed [70], with an attempt to research the deformation characteristics during two stages of decay creep and stable creep of surrounding rock. 


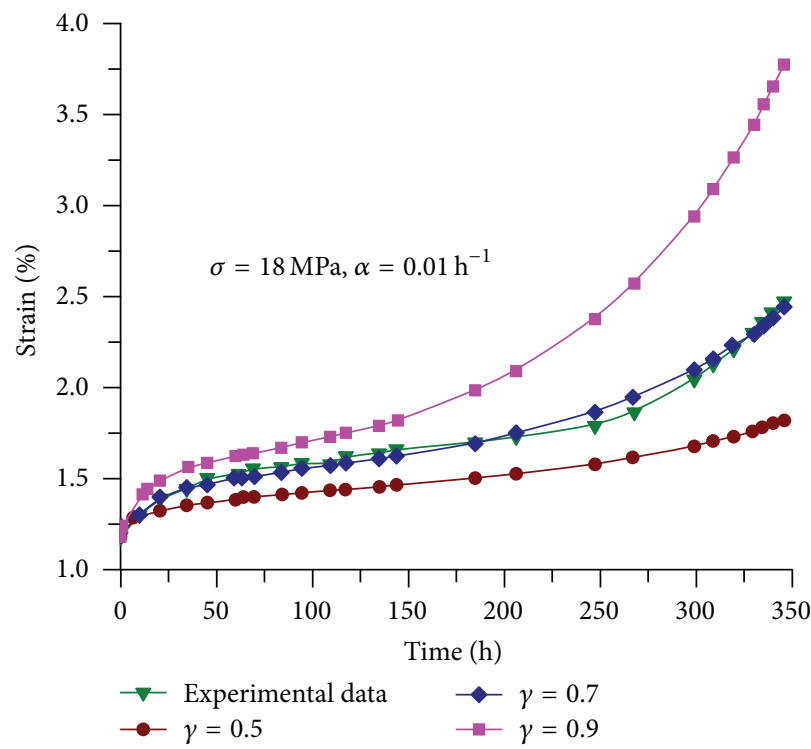

(a) Parameter $\gamma$

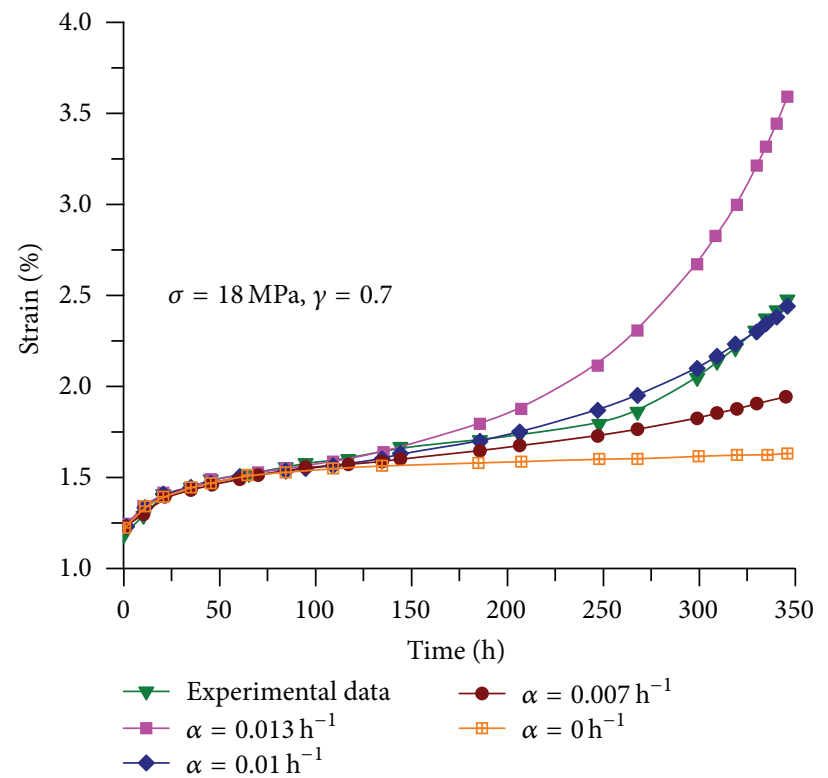

(b) Parameter $\alpha$

FIGURE 12: Sensitivity of the creep strain to the fractional derivative order in the case [61].

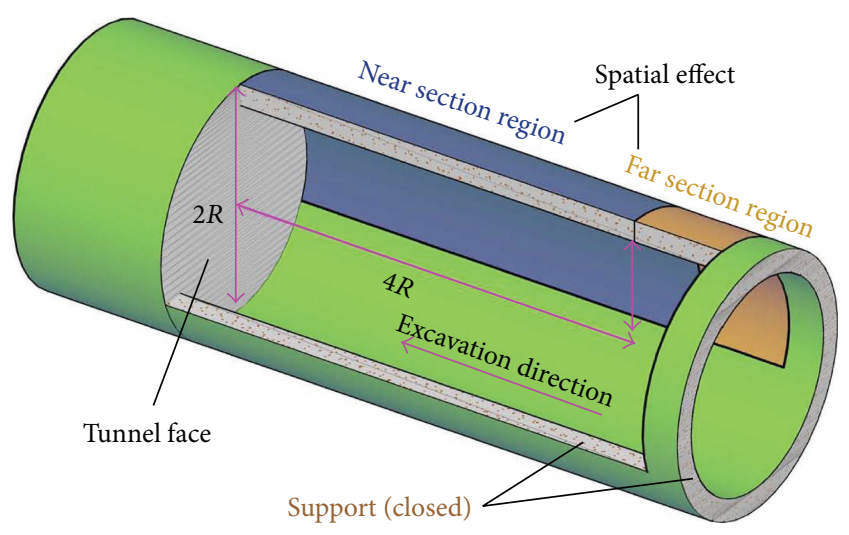

FIGURE 13: Tunnel excavation.

When we analyze the case of tunnel without support, taking the displacement calculation of tunnel without sidewall as an example, the creep displacement of its far section region is investigated [71], that is, neglecting the influence of tunnel face with $\lambda=1$. Thus the viscoelastic solution for sidewall displacement in far section region based on fractional derivative Maxwell model is obtained:

$$
U_{r}(t)=\frac{\sigma_{0} b^{2}}{2 r}\left[\frac{1}{G}+\frac{1}{\eta} \frac{t^{\gamma}}{\Gamma(1+\gamma)}\right], \quad(0 \leq \gamma \leq 1) .
$$

The parameters of both Burgers model and fractional derivative Maxwell model are firstly confirmed with particle swarm optimization, and then the displacement values of tunnel sidewall in different periods are gained, depicted in Figure 14. With the duration time of 1000 days, Figure 14(a) denotes that the description of fractional derivative Maxwell model is essentially equivalent to classical model. But when the duration time comes to 10000 days, the calculation results of two models are close to being consistent only in a certain period of time, rather than the whole procedure, shown in Figure 14(b). In greater detail, it indicates that, compared with the fractional derivative Maxwell model, the calculation results change greatly with time especially in later stage based on Burgers model.

Under the circumstance of support measures, as shown in Figure 15, the impacts of the interaction between tunnel face and support and surrounding rock and support need to be considered simultaneously [72]. It is assumed that time $t_{0}$ has passed when support structure is performed, in the case of $t<t_{0}$, representing the state before the support structure is applied, while $t=t_{0}$ represents the state of performing the support structure. Additionally, the hypothesis is proposed that the process of performing the support structure is completed instantaneously, indicating that no displacement is produced during the installation of support. Thus the viscoelastic solution for sidewall displacement in far section region $(\lambda=1)$ based on fractional derivative Maxwell model is obtained:

$$
U_{b}(t)=\frac{\sigma_{0} b}{K_{s}+2 G^{*}(t)}\left[1+\frac{K_{s}}{2 G}\right],
$$

where the stiffness of supporting structure can be estimated by the empirical formula proposed by Brady and Brown [73]:

$$
K_{s}=\frac{E^{\prime}\left(b^{2}-a^{2}\right)}{\left(1+v^{\prime}\right)\left[\left(1-2 v^{\prime}\right) b^{2}+a^{2}\right]} .
$$

Subsequently, the displacement values of tunnel sidewall were depicted in Figure 16 with the same methods as mentioned previously. It can be known that the change trends of sidewall displacement based on the fractional derivative 


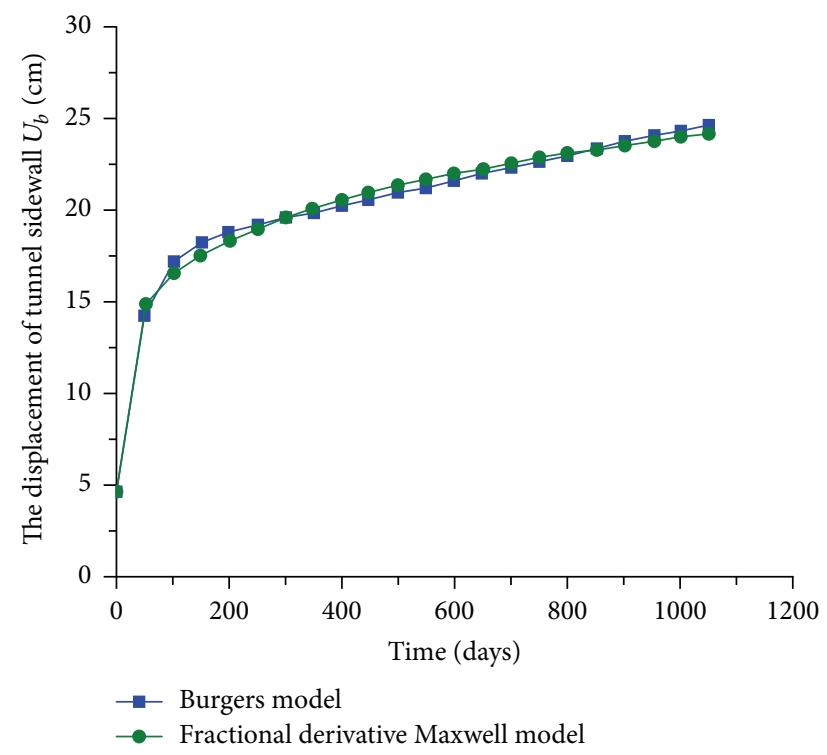

(a) 0-1000 days

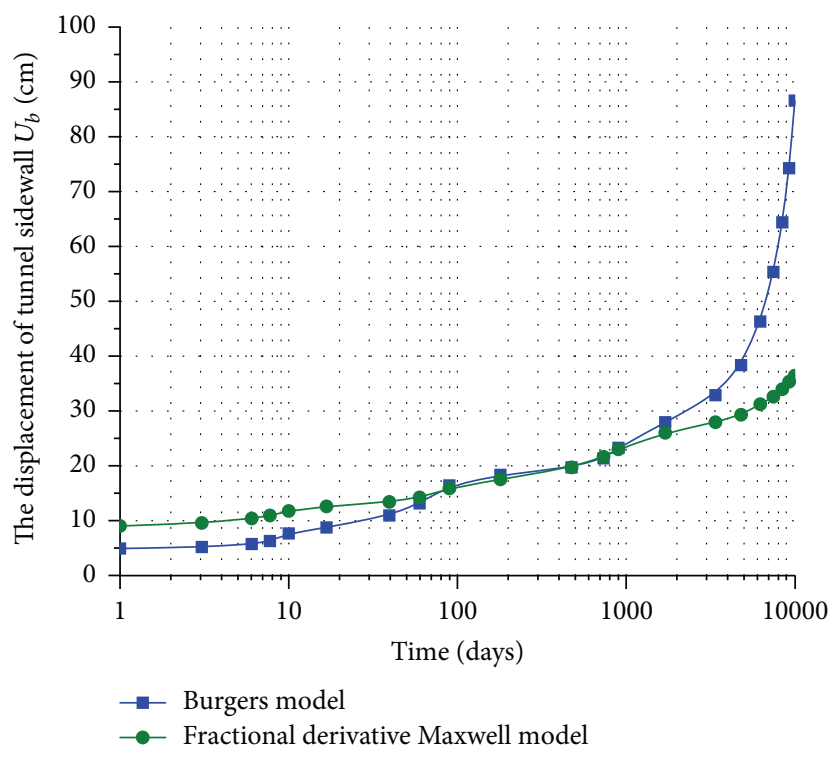

(b) 0-10000 days

FIgURE 14: The creep displacement of tunnel sidewall without support [69].

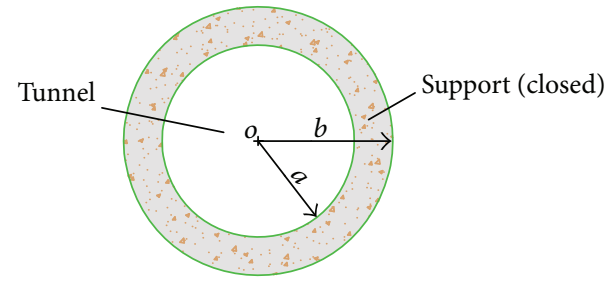

FIGURE 15: Schematic diagram of support.

Maxwell model are basically consistent with Burgers model in the range of $0 \sim 10^{10}$ days. Furthermore, the deformation results of two kinds of models tend to be convergent with the same final value, caused by the equation $\lim _{t \rightarrow \infty} G(t)=$ $\lim _{t \rightarrow \infty}(1 / J(t))=0$. Moreover, through the comparative analysis of Figures 14 and 16, it is shown that the displacement value of tunnel sidewall decreases significantly and then tends to be convergent after working of support structure.

4.2. Rheological Settlement of Subgrade. Mentioned in traditional consolidation theory, the soil skeleton is usually regarded as elastomer with pore water pressure [74]. In relation to this, the additional stress formula of embankment is established with an assumption that foundation is considered as an ideal linear elasticity [75, 76]. However, in practical road engineering, the state of embankment foundation is more than extremely complicated with mechanical property of distinct viscoelasticity, which mainly depends on structure composition, temperature, load frequency and load history, and so forth. At the consolidation time scale, processes such as settlement of subgrade can be approached by creep deformation, subjected to a viscous rheology.

On the basis of viscoelastic theory and in combination with the characterization of subgrade fill, Wang [77] utilized

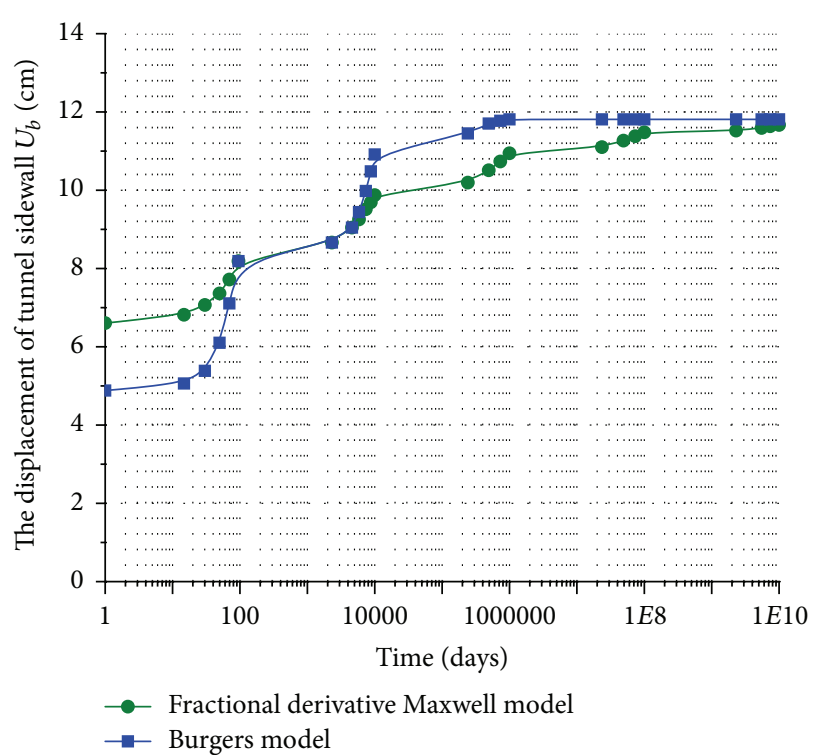

FIGURE 16: The creep displacement of tunnel sidewall after supporting [69].

the fractional derivative Kelvin-Voigt model and simplified the rheological settlement problem of embankment with high fill to be a plane strain problem. Meanwhile, the EDJ-1 type device from Nanjing Soil Instrument Factory was selected, as shown in Figure 17, devoted to undertake shear creep test on compacted soil. The stress-strain relationship was confirmed by the rheological constitutive model subsequently, which was established through the curve cluster of consolidation creep under step loading as shown in Figure 18.

In greater detail, taking the corresponding load stress $\sigma_{0}$ and $\sigma_{0}+\Delta \sigma$ as example, the curves of consolidation 


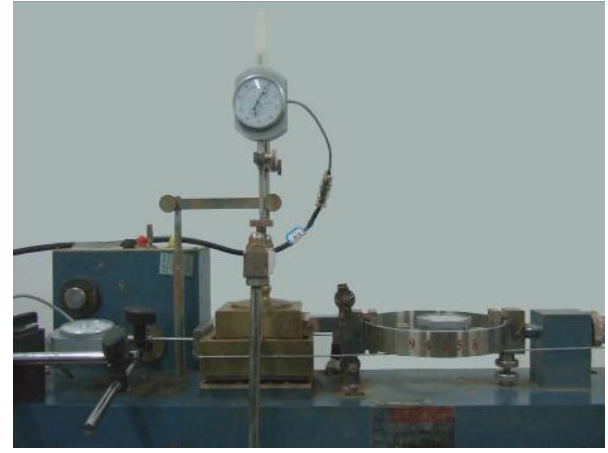

FIGURE 17: The main test device [77].

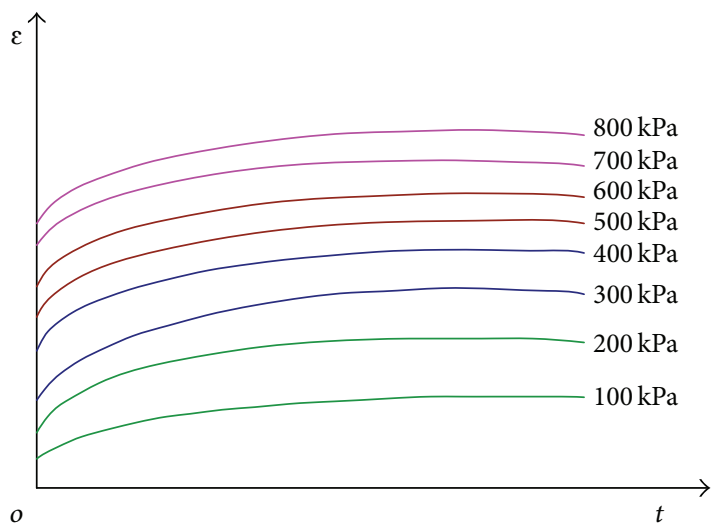

FIGURE 18: Sketch of curve cluster [77].

creep were obtained from the experimental data treated by linear interpolation. Furthermore, through subtracting correspondingly the curve values of the load stress $\sigma_{0}+\Delta \sigma$ from $\sigma_{0}$, the consolidation creep law at a certain depth resulted from the fact that additional load $\Delta \sigma$ could be calculated; thus parameters were determined through parameter identification subsequently [78]. In terms of practical subgrade, according to the method as mentioned above, consolidation creep test was performed to each layer of stratified subgrade [79-81], following acquirement of the parameters of model for each layer. Hence, the total settlement of foundation within compressed layer was given by [77]

$$
\begin{aligned}
S & =\sum_{i=1}^{n} \Delta S_{i}=q \sum_{i=1}^{n} \Delta \eta_{i}(x, z) \\
& \cdot\left\{\frac{1}{E_{0 i}}+\frac{1}{E_{1 i}}\left\{1-E_{\gamma_{i}, 1}\left[-\alpha_{i}^{\gamma_{i}}\left(\frac{t}{\tau}\right)^{\gamma_{i}}\right]\right\}\right\} H_{i},
\end{aligned}
$$

where $H_{i}$ refers to the layer thickness of foundation and its determination method is the same as the layer-wise summation method.

4.3. Relevant Loess Researches. Through replacing Newton dashpot in classical model with Abel dashpot, Gen et al. [59] established fractional derivative standard linear model, and its analytical expression of shear stress relaxation was

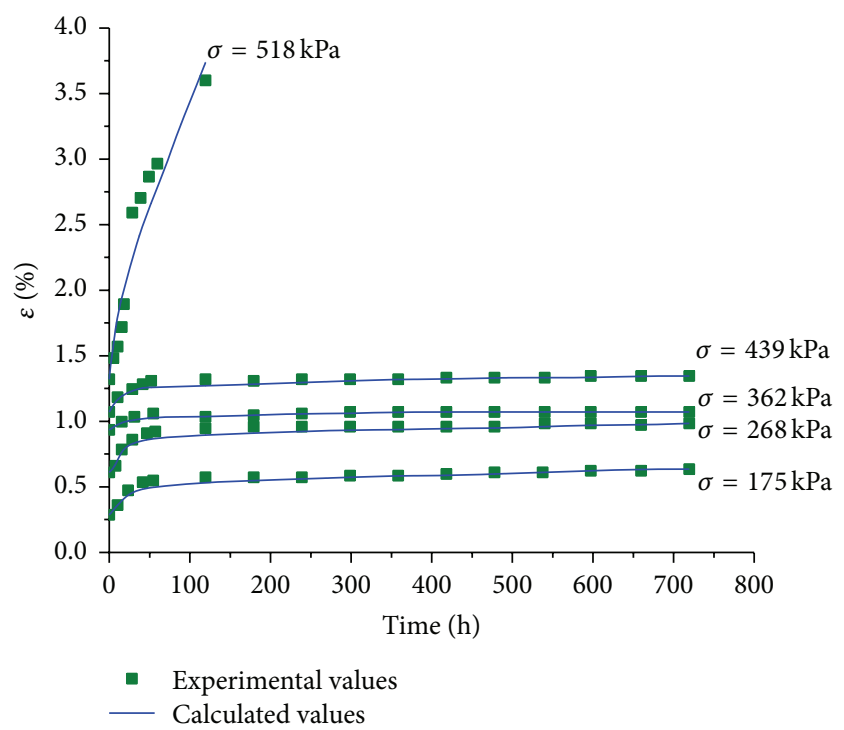

FIGURE 19: Test values and theoretic values for creep of loess sample (moisture content 8\%) [80].

obtained. Furthermore, the test for direct shear relaxation was conducted under the conditions of different positive pressure for Malan loess with different water contents, resulting in the conclusion that the relaxation features of Malan loess could be represented effectively by the proposed model subjected to fitting verification.

Taking water damage variable $D_{\omega}$ of $Q_{2}$ loess into account, Tang et al. [82] obtained the equations of water damage evolution in terms of various creep parameters accordingly. Through introducing Abel dashpot with variable coefficient, the nonlinear creep model of $Q_{2}$ loess was established; thus its constitutive equation for creep behavior was given by [82]

$$
\begin{aligned}
& \varepsilon(t, \omega) \\
& = \begin{cases}\frac{\sigma}{E_{H}^{*}}+\frac{\sigma}{\eta_{1}^{*}} \frac{t^{\gamma_{1}}}{\Gamma\left(1+\gamma_{1}\right)}, & \sigma \leq \sigma_{s}, \\
\frac{\sigma}{E_{H}^{*}}+\frac{\sigma}{\eta_{1}^{*}} \frac{t^{\gamma_{1}}}{\Gamma\left(1+\gamma_{1}\right)}+\frac{\sigma-\sigma_{s}}{\eta_{2}} \frac{t^{\gamma_{2}}}{\Gamma\left(1+\gamma_{2}\right)}, & \sigma \geq \sigma_{s},\end{cases}
\end{aligned}
$$

where $E_{H}^{*}=E_{H}\left[-D_{\varepsilon_{H}(\omega)}\right], \eta_{1}^{*}=\eta_{1}\left[1-D_{\varepsilon_{H}(\omega)}\right], 0<\gamma_{1}<1$, $\gamma_{2}>1$.

In addition, to verify the correctness and accuracy of the obtained constitutive equation, a series of triaxial creep tests to $Q_{2}$ loess under different states of water content was undertaken. Meanwhile, based on the test data, the regression analysis for parameters estimation was performed using 1stOpt mathematical software. In the case of water content of $8 \%$, five group curves of model theoretical values and experimental values were depicted in Figure 19, representing different procedure. For a comparison, it exhibits that the established model for $Q_{2}$ loess is able to characterize effectively each stage of the instantaneous deformation, decay creep, steady creep, and accelerated creep, thus having a bright future for application. 


\section{Summary and Perspectives}

For the purpose of describing the rheology phenomena in geotechnical engineering, this paper has provided an up-todate review of key constitutive models in combination with model structure and acquisition of parameters. Compared with classical constitutive model, the fractional derivative models have shown the extruding advantage of more concise equation, fewer parameters, and higher precision, which also have been improved, amended, and perfected constantly. Currently, with the significant improvement of numerical methods, the parameter of the fractional derivative model that is rather difficult to determine in the pass time has not been the fetters to hinder the research; thus the application of fractional derivative models in geotechnical engineering has been successful with gradually mature technology. We therefore comprehensively reviewed the state-of-theart of fractional derivative model for practical application, including three major aspects of deformation analysis of circular tunnel, rheological settlement of the subgrade, and relevant loess researches. To some extent, the rheological models based on fractional calculus are developing toward precision, theorization, design of three dimensions, and so forth and have established a better research framework. However, through the application case analysis and summary mentioned above, we can obtain the following conclusions and perspectives.

(1) As a powerful mathematical tool, the fractional derivative models have advantage of describing effectively the whole procedure of rheology phenomenon and are endowed with a small number of parameters. Nevertheless, along with the constant refinement of analysis and design in geotechnical engineering, what is crucial and then is proposed during the process of application is a higher demand on parameters precision. Therefore, how to obtain more precise parameters based on experimental data is the target that investigators assiduously seek. Meanwhile, theoretical research ought to be deepened and tends to clear the physical significance and find out its change laws of some parameters such as $\gamma$ and $\eta$.

(2) The application case analysis shows that the description of the fractional derivative model has a preferable applicability, by adjusting the fractional derivative order of fractional derivative dashpot. In other words, the fractional derivative model is one of the most effective ways to describe the rheology, which is more flexible for the dynamic deformation. But we need to know that fractional derivative model has many restrictions in the actual application of engineering; for instance, the tunnel under study is assumed to be horizontally circular. Therefore, actual experiences should be accumulated in the processing of engineering, and on this basis the applicability of fractional derivative model ought to keep on improving. Specifically, monitoring in situ test of tunneling should be strengthened, and then the predictive value for corresponding deformation will be gained in combination with the research on accelerated stage of creep. Moreover, in order to ensure the safety of construction site and avoid the occurrence of accident in the long run, the fractional derivative model should be applied to predict the failure phenomena such as collapse and large deformation of tunnel engineering.

(3) According to the complicated problems of geotechnical engineering, the results obtained based on classical model due to its limitation deviate largely from the actual field condition. Obviously, the current finite element software programs, which are based on classical constitutive model, are powerless in numerical simulation. Furthermore, owing to the bad potential of operation and cost-effectiveness, laboratory simulation experiment has difficulty in satisfying engineering demands. Considering the complicated mechanics properties of practical engineering, it is necessary to deepen the investigation on three-dimensional fractional derivative model. Moreover, it can be envisaged that fractional derivative model would be more suitable for the analysis of engineering problems in the coming years, especially if the existing numerical software is equipped with fractional derivative models by conducting secondary development.

(4) In the field of geotechnical engineering, there were accumulated numerous constitutive models (including classical models and fractional models) with diversified forms. Hence, it is essential to conclude and summarize the existing identification technologies, and then constitutive model database of geotechnical materials should be established in combination with various identification algorithms, devoted to the convenient choices and efficient applications with clear classification of constitutive models. For instance, the fractional derivative Maxwell model should be labeled as one that can only describe the rheology whose initial value tends toward zero, which is not applicable to the case of compacted soil. Finally, taking our results into consideration, a constitutive model based on fractional derivative, which is concise and is able to describe rheology phenomenon accurately, may be incorporated into model database and may be the best choice in the future.

\section{Competing Interests}

The authors declare that there is no conflict of interests regarding the publication of this paper.

\section{Acknowledgments}

This work is financially supported by the Brainstorm Project on Social Development of Shaanxi Provincial Science and Technology Department (Grant No. 2016SF-412) and the Special Fund for Basic Scientific Research of Central Colleges of Changan University (Grant no. 31082116011) and the Key Industrial Research Project of Shaanxi Provincial Science and Technology Department (Grant no. 2015GY185) and the Integrated Innovation Project of Shaanxi Provincial Science and Technology Department (Grant no. 2015KTZDGY01-05$02)$.

\section{References}

[1] D. Yin, W. Zhang, C. Cheng, and Y. Li, "Fractional timedependent Bingham model for muddy clay," Journal of NonNewtonian Fluid Mechanics, vol. 187-188, pp. 32-35, 2012. 
[2] H. W. Zhou, C. P. Wang, B. B. Han, and Z. Q. Duan, "A creep constitutive model for salt rock based on fractional derivatives," International Journal of Rock Mechanics and Mining Sciences, vol. 48, no. 1, pp. 116-121, 2011.

[3] Y. P. Yao, B. Y. Zhang, and J. G. Zhu, "Behaviors, constitutive models and numerical simulation of soils," Tumu Gongcheng Xuebao/China Civil Engineering Journal, vol. 45, no. 3, pp. 127150, 2012.

[4] Z.-C. Wang and L.-P. Qiao, "A review and discussion on creep behavior of soil and its models," Rock and Soil Mechanics, vol. 32, no. 8, pp. 2251-2260, 2011.

[5] D. M. Cruden, "The form of the creep law for rock under uniaxial compression," International Journal of Rock Mechanics and Mining Sciences \& Geomechanics Abstracts, vol. 8, no. 2, pp. 105126, 1971.

[6] M. Oeser and T. Pellinien, "Computational framework for common visco-elastic models in engineering based on the theory of rheology," Computers and Geotechnics, vol. 42, pp. 145156, 2012.

[7] H. Zhang, Z. Y. Wang, Y. Zheng, P. J. Duan, and S. Ding, "Study on tri-axial creep experiment and constitutive relation of different rock salt," Safety Science, vol. 50, no. 4, pp. 801-805, 2012.

[8] A. Heibig and L. I. Palade, "Well posedness of a linearized fractional derivative fluid model," Journal of Mathematical Analysis and Applications, vol. 380, no. 1, pp. 188-203, 2011.

[9] G. B. Davis, M. Kohandel, S. Sivaloganathan, and G. Tenti, "The constitutive properties of the brain paraenchyma. Part 2. Fractional derivative approach," Medical Engineering and Physics, vol. 28, no. 5, pp. 455-459, 2006.

[10] H.-A. A. Rafael, R.-O. M. Pedro, M. del Toro Roberto, and C.-B. Jorge, "Simulation of creep phenomenon in clay soils using rheology and fractional differential equations," Ingeniería, Investigación y Tecnología, vol. 15, no. 4, pp. 561-574, 2014.

[11] F. Barpi and S. Valente, "A fractional order rate approach for modeling concrete structures subjected to creep and fracture," International Journal of Solids and Structures, vol. 41, no. 9-10, pp. 2607-2621, 2004.

[12] T. Pritz, "Five-parameter fractional derivative model for polymeric damping materials," Journal of Sound and Vibration, vol. 265, no. 5, pp. 935-952, 2003.

[13] P. Yang, Y. C. Lam, and K.-Q. Zhu, "Constitutive equation with fractional derivatives for the generalized UCM model," Journal of Non-Newtonian Fluid Mechanics, vol. 165, no. 3-4, pp. 88-97, 2010.

[14] V. A. Vyawahare and P. S. V. Nataraj, "Fractional-order modeling of neutron transport in a nuclear reactor," Applied and Mathematial Modelling, vol. 37, no. 23, pp. 9747-9767, 2013.

[15] R. Droghei and E. Salusti, "A comparison of a fractional derivative model with an empirical model for non-linear shock waves in swelling shales," Journal of Petroleum Science and Engineering, vol. 125, pp. 181-188, 2015.

[16] Z. Xu and W. Chen, "A fractional-order model on new experiments of linear viscoelastic creep of Hami Melon," Computers and Mathematics with Applications, vol. 66, no. 5, pp. 677-681, 2013.

[17] B. Li and W. Xie, "Adaptive fractional differential approach and its application to medical image enhancement," Computers and Electrical Engineering, vol. 45, pp. 324-335, 2015.

[18] B. J. West, "Fractional calculus in bioengineering," Journal of Statistical Physics, vol. 126, no. 6, pp. 1285-1286, 2007.
[19] C. Celauro, C. Fecarotti, A. Pirrotta, and A. C. Collop, "Experimental validation of a fractional model for creep/recovery testing of asphalt mixtures," Construction and Building Materials, vol. 36, pp. 458-466, 2012.

[20] A. Schmidt and L. Gaul, "On the numerical evaluation of fractional derivatives in multi-degree-of-freedom systems," Signal Processing, vol. 86, no. 10, pp. 2592-2601, 2006.

[21] L. Deseri, M. D. Paola, and M. Zingales, "Free energy and states of fractional-order hereditariness," International Journal of Solids and Structures, vol. 51, no. 18, pp. 3156-3167, 2014.

[22] J. H. Kang, F. Z. Zhou, C. Liu, and Y. Liu, "A fractional nonlinear creep model for coal considering damage effect and experimental validation," International Journal of Non-Linear Mechanics, vol. 76, pp. 20-28, 2015.

[23] M.-M. He, N. Li, Y.-S. Chen, and C.-H. Zhu, "Dynamic deformation behavior of rock based on fractional order calculus," Chinese Journal of Geotechnical Engineering, vol. 37, no. s1, pp. 178-184, 2015.

[24] C. C. Zhang, H. H. Zhu, B. Shi et al., "Theoretical investigation of interaction between a rectangular plate and fractional viscoelastic foundation," Journal of Rock Mechanics and Geotechnical Engineering, vol. 45, pp. 324-335, 2015.

[25] W. Chen, H. G. Sun, and X. C. Li, Mechanical and Engineering Problems of Fractional Derivative Model, Science Press, Beijing, China, 2012.

[26] A. Gemant, "A method of analyzing experimental results obtained from elasto-viscous bodies," Journal of Applied Physics, vol. 7, no. 8, pp. 311-317, 1936.

[27] B. B. Mandelbrot, The Fractal Geometry of Nature, Freeman, San Francisco, Calif, USA, 1982.

[28] V. O. Shestopal and P. C. J. Goss, "The estimation of column creep buckling durability from the initial stages of creep," Acta Mechanica, vol. 52, no. 3-4, pp. 269-275, 1984.

[29] R. L. Bagley and P. J. Torvik, "On the fractional calculus model of viscoelastic behavior," Journal of Rheology, vol. 30, no. 1, pp. 133-155, 1986.

[30] W. M. Zhang, "A new rheological model theory with fractional order derivatives," Natural Science Journal of Xiangtan University, vol. 23, no. 1, pp. 31-36, 2001.

[31] R. Metzler and T. F. Nonnenmacher, "Fractional relaxation processes and fractional rheological models for the description of a class of viscoelastic materials," International Journal of Plasticity, vol. 19, no. 7, pp. 941-959, 2003.

[32] D. S. Yin, J. J. Ren, C. L. He, and W. Chen, "New rheological model element for geomaterials," Chinese Journal of Rock Mechanics and Engineering, vol. 26, no. 9, pp. 1899-1903, 2007.

[33] K. B. Oldham and J. Spanier, The Fractional Calculs, Academic Press, New York, NY, USA, 1974.

[34] T. F. Nonnenmacher and R. Metzler, "On the Riemann-Liouville fractional calculus and some recent applications," Fractals, vol. 3, no. 3, pp. 557-566, 1995.

[35] G. Rudolf and M. Francesco, Essentials of Fractional Calculus, MaPhySto Center, Aarhus, Denmark, 2000.

[36] X. Wang, Genetic fractional order derivative of artificial frozen soil creep constitutive model research [Ph.D. thesis], Anhui University of Science and Technology, 2013.

[37] F. Wu, J.-F. Liu, Z.-D. Wu, Y. Bian, and Z.-W. Zhou, "Fractional nonlinear creep constitutive model of salt rock," Rock and Soil Mechanics, vol. 35, no. s8, pp. 162-167, 2014.

[38] R. F. Meng, D. S. Yin, C. Zhou, and H. Wu, "Fractional description of time-dependent mechanical property evolution in 
materials with strain softening behavior," Applied Mathematical Modelling. Simulation and Computation for Engineering and Environmental Systems, vol. 40, no. 1, pp. 398-406, 2016.

[39] Q. Li, K. H. Wang, and K. H. Xie, "Recognition of models and back analysis of parameters for artificial frozen soils," Rock and Soil Mechanics, vol. 23, no. 11, pp. 1895-1899, 2004.

[40] C. Zopf, S. E. Hoque, and M. Kaliske, "Comparison of approaches to model viscoelasticity based on fractional time derivatives," Computational Materials Science, vol. 98, pp. 287296, 2015.

[41] B.-R. Chen, X.-J. Zhao, X.-T. Feng, H.-B. Zhao, and S.-Y. Wang, "Time-dependent damage constitutive model for the marble in the Jinping II hydropower station in China," Bulletin of Engineering Geology and the Environment, vol. 73, no. 2, pp. 499-515, 2014.

[42] R. Lewandowski and B. Chorążyczewski, "Identification of the parameters of the Kelvin-Voigt and the Maxwell fractional models, used to modeling of viscoelastic dampers," Computers and Structures, vol. 88, no. 1-2, pp. 1-17, 2010.

[43] T. Beda, "An approach for hyperelastic model-building and parameters estimation a review of constitutive models," European Polymer Journal, vol. 50, no. 1, pp. 97-108, 2014.

[44] Y. J. Song and S. Y. Lei, "Mechanical model of rock nonlinear creep damage based on fractional calculus," Chinese Journal of Underground Space and Engineering, vol. 9, no. 1, pp. 91-122, 2013.

[45] M. Caputo and M. Fabrizio, "Damage and fatigue described by a fractional derivative model," Journal of Computational Physics, vol. 293, pp. 400-408, 2015.

[46] H.-Z. Sun and W. Zhang, "Analysis of soft soil with viscoelastic fractional derivative Kelvin model," Yantu Lixue/Rock and Soil Mechanics, vol. 28, no. 9, pp. 1983-1986, 2007.

[47] R. D. Li and J. C. Yue, "Nonlinear rheological constitute of soft soil based on fractional order derivative theory," Journal of Basic Science and Engineering, vol. 22, no. 5, pp. 856-864, 2014.

[48] L.-J. He, L.-W. Kong, W.-J. Wu, X.-W. Zhang, and Y. Cai, "A description of creep model for soft soil with fractional derivative," Rock and Soil Mechanics, vol. 32, no. 2, pp. 239-249, 2011.

[49] R. C. Koeller, "Applications of fractional calculus to the theory of viscoelasticity," Journal of Applied Mechanics, vol. 51, no. 2, pp. 299-307, 1984.

[50] J. Ding, H. Zhou, D. Liu, Q. Chen, and J. Liu, "Research on fractional derivative three elements model of salt rock," Chinese Journal of Rock Mechanics and Engineering, vol. 33, no. 4, pp. 672-678, 2014.

[51] Z. M. Yao, Y. Zhou, Y. Xu et al., "Genetic algorithms fractional order derivative burgers creep model for artificial frozen soil," Industrial Construction, vol. 43, no. 11, pp. 73-76, 2013.

[52] Y.-G. Kang and X.-E. Zhang, "Nonstationary parameter fractional burgers model of rock creep," Rock and Soil Mechanics, vol. 32, no. 11, pp. 3237-3248, 2011.

[53] X. Zhao, Identification of fractional viscoelastic constitutive parameters [Ph.D. thesis], Dalian University of Technology, 2012.

[54] J.-H. Chen, Z.-M. Yao, Y. Xu, and H.-L. Wang, "Particle swarm fractional order derivative model of artificial frozen soil creep properties," Journal of the China Coal Society, vol. 38, no. 10, pp. 1763-1768, 2013.

[55] L. S. Niu, Study of laboratory prepared frozen soil property and fractional order derivative Nishihara model [Ph.D. thesis], Anhui University of Science and Technology, Huainan, China, 2014.
[56] Y. R. Liu and H. M. Tang, Rockmass Mechanics, Chemical Industry Press, Beijing, China, 2008.

[57] J. Liu, Experimental investigation and theoretic analysis on the mechanical properies of layered rock salt [Ph.D. thesis], Institute of Rock and Soil Mechanics, Chinese Academy of Sciences, 2006.

[58] G.-W. Xu, C. He, X.-Y. Hu, and S.-M. Wang, "A modified Nishihara model based on fractional calculus theory and its parameter intelligent identification," Rock and Soil Mechanics, vol. 36, no. 2, pp. 132-147, 2015.

[59] X. F. Gen, B. X. Li, and T. D. Miao, "Study on shear stress relaxation properties of Malan loess," Northwestern Seismological Journal, vol. 32, no. 1, pp. 36-41, 2010.

[60] Q. F. He, Study on the mechanical and rheological properties of Yanian Q2 Loess [Ph.D. thesis], Chang'an University, Xian, China, 2008.

[61] H. W. Zhou, C. P. Wang, Z. Q. Duan, M. Zhang, and J. F. Liu, "Time-based fractional derivative approach to creep constitutive model of salt rock," Scientia Sinica Physica, Mechanica \& Astronomica, vol. 42, no. 3, pp. 310-318, 2012.

[62] L.-C. Liu and W. Zhang, "Deformation properties of horizontal round adits in viscoelastic rocks with fractional Kelvin model," Rock and Soil Mechanics, vol. 26, no. 2, pp. 287-289, 2005.

[63] T. Z. Yang and B. Fang, "Asymptotic analysis of an axially viscoelastic string constituted by a fractional differentiation law," International Journal of Non-Linear Mechanics, vol. 49, pp. 170-174, 2013.

[64] Z. L. He, Z. D. Zhu, N. Wu, Z. Wang, and S. Cheng, "Study on time-dependent behavior of granite and the creep model based on fractional derivative approach considering temperature," Mathematical Problems in Engineering, vol. 2016, Article ID 8572040, 10 pages, 2016.

[65] H.-P. Lai, S.-Y. Wang, and Y.-L. Xie, "Experimental research on temperature field and structure performance under different lining water contents in road tunnel fire," Tunnelling and Underground Space Technology, vol. 43, pp. 327-335, 2014.

[66] J. X. Lai, J. L. Qiu, Z. H. Feng, J. Chen, and H. Fan, "Prediction of soil deformation in tunnelling using artificial neural networks," Computational Intelligence and Neuroscience, vol. 2016, Article ID 6708183, 16 pages, 2016.

[67] C. Cao, T. Ren, and C. Cook, "Calculation of the effect of Poisson's ratio in laboratory push and pull testing of resinencapsulated bolts," International Journal of Rock Mechanics and Mining Sciences, vol. 64, pp. 175-180, 2013.

[68] D. S. Yin, X. M. Duan, and X. J. Zhou, "Fractional timedependent deformation component models for characterizing viscoelastic Poisson's ratio," European Journal of MechanicsA/Solids, vol. 42, pp. 422-429, 2013.

[69] L. Chen, A study on rheological characteristics of soft rock tunnel with a deep overburden [Ph.D. thesis], Southwest Jiaotong University, Chengdu, China, 2014.

[70] J. X. Lai, J. L. Qiu, J. X. Chen, H. Fan, and K. Wang, "New technology and experimental study on snow-melting heated pavement system in tunnel portal," Advances in Materials Science and Engineering, vol. 2015, Article ID 706536, 11 pages, 2015.

[71] J. Lai, C. Guo, J. Qiu, and H. Fan, "Static analytical approach of moderately thick cylindrical ribbed shells based on firstorder shear deformation theory," Mathematical Problems in Engineering, vol. 2015, Article ID 274091, 14 pages, 2015. 
[72] J. Lai, H. Fan, J. Chen, J. Qiu, and K. Wang, "Blasting vibration monitoring of undercrossing railway tunnel using wireless sensor network," International Journal of Distributed Sensor Networks, vol. 2015, Article ID 703980, 7 pages, 2015.

[73] B. Brady and E. Brown, Rock Mechanic for Underground Mining, George Allen \& Unwin, London, UK, 1st edition, 1985.

[74] K.-H. Xie, M.-M. Lu, A.-F. Hu, and G.-H. Chen, "A general theoretical solution for the consolidation of a composite foundation," Computers and Geotechnics, vol. 36, no. 1-2, pp. 24-30, 2009.

[75] J. X. Lai, H. Q. Liu, J. L. Qiu, and J. Chen, "Settlement analysis of saturated tailings dam treated by CFG pile composite foundation," Advances in Materials Science and Engineering, vol. 2016, Article ID 7383762, 10 pages, 2016.

[76] M.-H. Zhao, X.-J. Zhan, and X.-J. Zou, "Numerical simulation of pile installation and subsequent consolidation in clay," Journal of Hunan University Natural Sciences, vol. 40, no. 2, pp. $1-8,2013$.

[77] Z. C. Wang, Research on constitutive model and its calculation method of high-filled embankment rheological settlement [Ph.D. thesis], Xiangtan University, Xiangtan, China, 2011.

[78] Y. Xie and X. Yang, "Characteristics of a new-type geocell flexible retaining wall," Journal of Materials in Civil Engineering, vol. 21, no. 4, pp. 171-175, 2009.

[79] H. Zhang, Z. Wang, Y. Zheng, P. Duan, and S. Ding, "Study on tri-axial creep experiment and constitutive relation of different rock salt," Safety Science, vol. 50, no. 4, pp. 801-805, 2012.

[80] F. Song, J. M. Zhang, and G. R. Cao, "Experimental investigation of asymptotic state for anisotropic sand," Acta Geotechica, vol. 10, no. 5, pp. 571-585, 2015.

[81] H. N. Wang, Z. P. You, S. W. Goh, P. Hao, and X. M. Huang, "Laboratory evaluation on the high temperature rheological properties of rubber asphalt: a preliminary study," Canadian Journal of Civil Engineering, vol. 39, no. 10, pp. 1125-1135, 2012.

[82] H. Tang, Z. Duan, F.-S. Zhao, F. Song, and X.-N. Li, “Creep damage model of Q2 loess in consideration of moisture content based on fractional calculus," Journal of Yangtze River Scientific Research Institute, vol. 32, no. 8, pp. 78-83, 2015. 


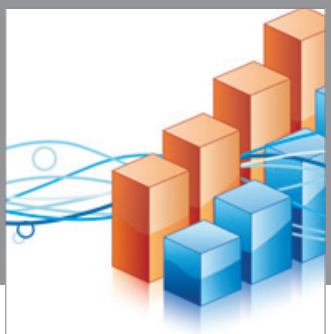

Advances in

Operations Research

vatem alat4

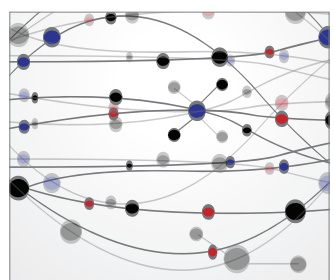

\section{The Scientific} World Journal
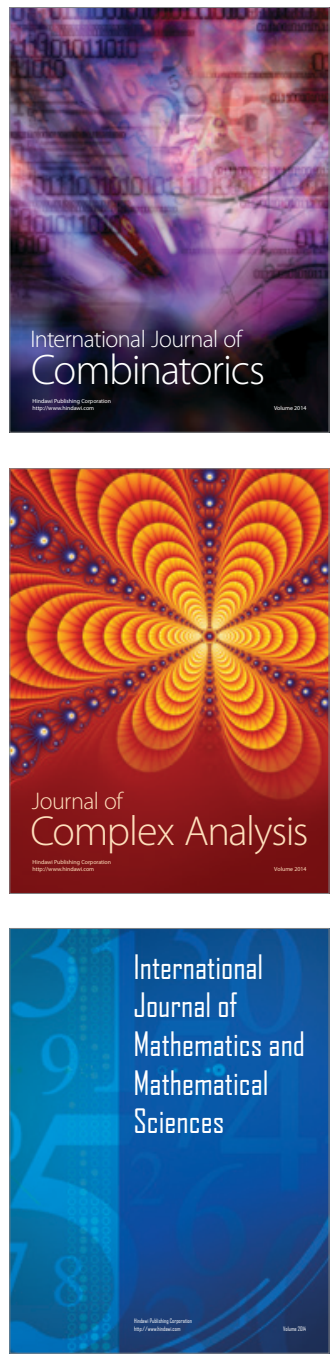
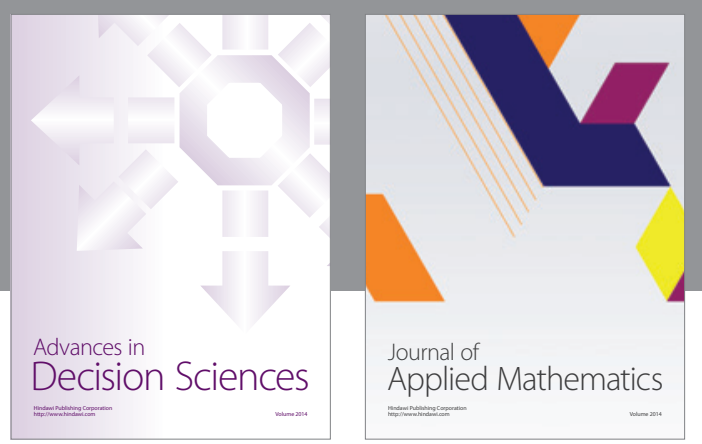

Algebra

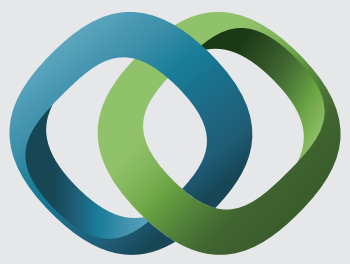

\section{Hindawi}

Submit your manuscripts at

http://www.hindawi.com
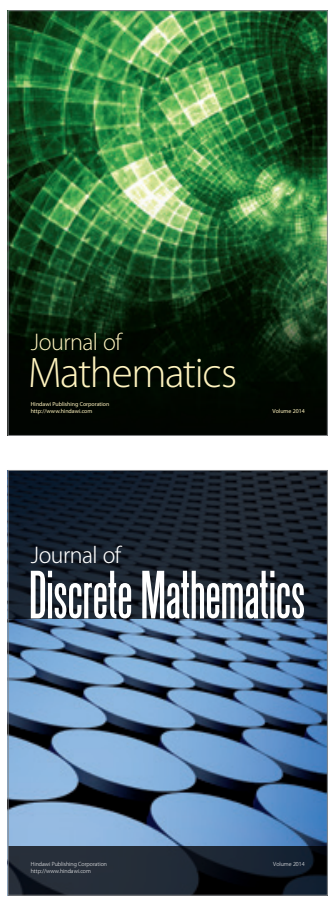

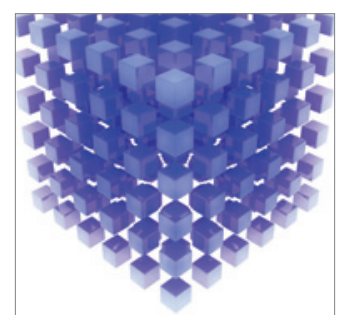

Mathematical Problems in Engineering
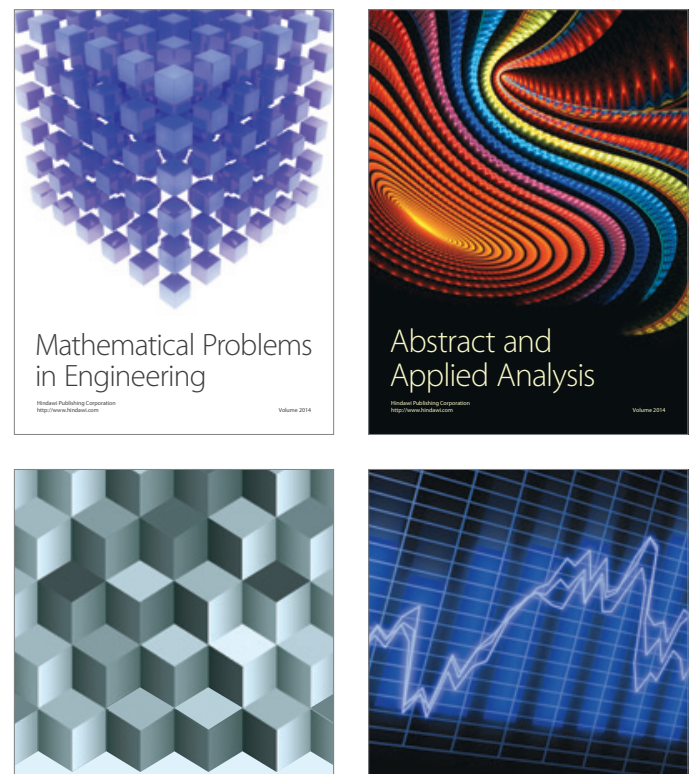

Journal of

Function Spaces

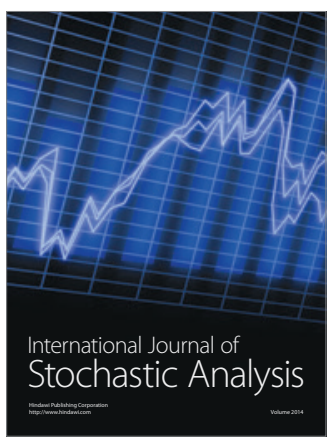

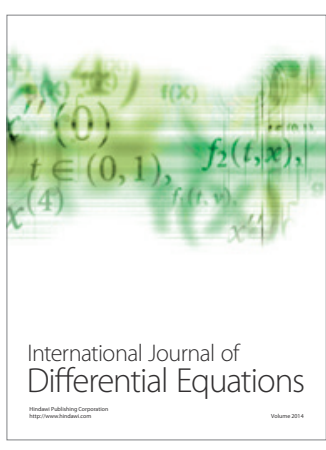
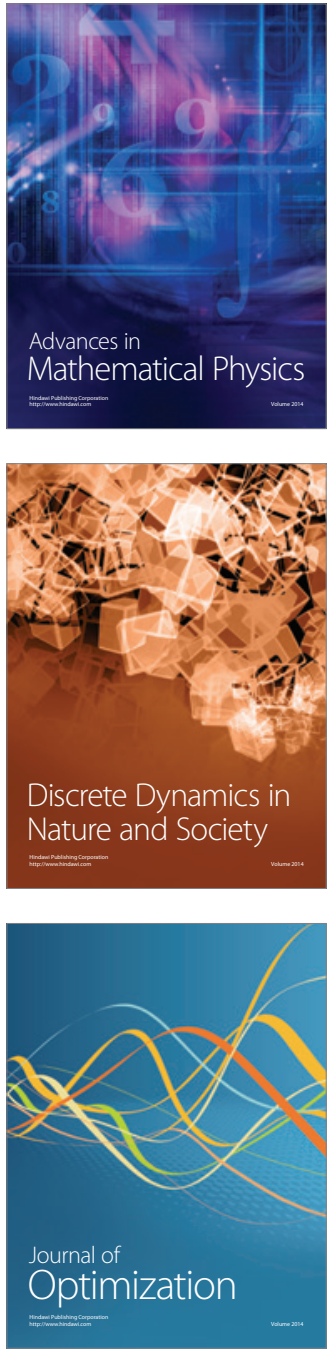